NBER WORKING PAPER SERIES

\title{
UNEQUAL JURY REPRESENTATION AND ITS CONSEQUENCES
}

\author{
Shamena Anwar \\ Patrick Bayer \\ Randi Hjalmarsson \\ Working Paper 28572 \\ http://www.nber.org/papers/w28572 \\ NATIONAL BUREAU OF ECONOMIC RESEARCH \\ 1050 Massachusetts Avenue \\ Cambridge, MA 02138 \\ March 2021, Revised August 2021
}

We thank Shari Diamond and seminar participants at the National Bureau of Economic Research, as well as the editors and three anonymous referees, for many helpful comments and suggestions. Hjalmarsson is grateful for the financial support of Vetenskapsrådet, The Swedish Research Council, Grants for Distinguished Young Researchers (VR 2014-01735). The views expressed herein are those of the authors and do not necessarily reflect the views of the National Bureau of Economic Research.

NBER working papers are circulated for discussion and comment purposes. They have not been peer-reviewed or been subject to the review by the NBER Board of Directors that accompanies official NBER publications.

(C) 2021 by Shamena Anwar, Patrick Bayer, and Randi Hjalmarsson. All rights reserved. Short sections of text, not to exceed two paragraphs, may be quoted without explicit permission provided that full credit, including (C) notice, is given to the source. 
Unequal Jury Representation and Its Consequences

Shamena Anwar, Patrick Bayer, and Randi Hjalmarsson

NBER Working Paper No. 28572

March 2021, Revised August 2021

JEL No. J15,K4

\section{ABSTRACT}

We analyze the extent and consequences of unequal representation on juries in Harris County, Texas. We first document that residents from predominantly white and high-income neighborhoods are substantially over-represented on juries. Using quasi-random variation in those called for jury duty each day, we next establish that Black defendants are more likely to be convicted and receive longer sentences from juries with more residents from these overrepresented neighborhoods. We estimate that equal representation would reduce Black defendants' median sentence length by $50 \%$ and the probability of receiving a life sentence by $67 \%$. Straightforward remedies could mitigate these legally unwarranted racial disparities.

Shamena Anwar

Rand Corporation

4570 Fifth Avenue

Pittsburgh, PA 15213

sanwar@rand.org

Patrick Bayer

Department of Economics

Duke University

213 Social Sciences

Durham, NC 27708

and NBER

patrick.bayer@duke.edu
Randi Hjalmarsson

University of Gothenburg

Department of Economics

PO Box 640

40530 Gothenburg

Sweden

hjalmarsson.randi@gmail.com 
The right to a trial by a jury of one's peers is a bedrock of American criminal law. Although legally required to reflect a fair cross section of the community, ${ }^{1}$ juries across the United States are often highly unrepresentative in practice, especially with respect to young, poor, transient, and racial minority populations. This study is motivated by the practical question of what can be done to address unequal jury representation in American criminal courts. We introduce a new measure of representation based on juror neighborhood (zip code), document the extent of unequal geographic representation in a major metropolitan court system, estimate its causal impact on trial outcomes, and discuss new actionable policies to remedy unequal representation using this measure.

Our empirical analysis is based on felony trial data from 2005 to 2012 and more than 300,000 individuals who responded to jury summons in Harris County, Texas, which includes Houston and has a population of about 4.7 million. These trials are particularly high stakes: about $70 \%$ of all felony trials involve defendants who are eligible for a life sentence. Nearly $60 \%$ of defendants are Black.

We conduct our analysis in three steps. First, we document the extent to which each neighborhood in the study area is represented in pre-trial jury panels and seated juries relative to that neighborhood's population share in the Census. We find substantial variation in representation across Harris County zip codes, with some having as little as 30 percent, and many over 200 percent, of their expected share of seated jurors. We also demonstrate that residents of predominantly white and high-income neighborhoods are substantially overrepresented on seated juries, while those from predominantly Black, Hispanic, and low-income neighborhoods are under-represented, sometimes severely so. Importantly, the vast majority of the variation in representation on seated juries is already reflected in the pool of potential jurors, with jury selection in the pre-trial voir dire process playing a comparatively small role. Unfortunately, our data (those who respond to summons) do not allow us to assess whether this variation already exists in the master list used to call jurors or results from disparate neighborhood response rates.

We next estimate the causal impact of jurors from each neighborhood on trial outcomes using a research design that isolates quasi-random day-to-day variation in the composition of potential jurors. Black defendants are much more likely to be convicted, receive more severe jury-determined sentences, and are much more likely to receive life sentences when eligible, if they (randomly) draw jury pools with a relatively high share of potential jurors from over-

\footnotetext{
${ }^{1}$ This language is drawn from Title 28 (Section 1861) of the U.S. code describing judiciary and judicial procedure.
} 
versus under-represented neighborhoods. Further analysis shows that these effects are strongly associated with neighborhood racial composition, among other factors.

Finally, we use these causal estimates to simulate the distribution of conviction rates and sentence lengths if juries were instead geographically representative of Harris County's neighborhoods. ${ }^{2}$ The results imply that the unequal representation of existing juries increases mean and median sentence lengths for Black defendants by over 50 percent and more than triples the likelihood that eligible Black defendants receive life sentences.

Why would equalizing neighborhood representation have such large impacts on Black sentencing outcomes? One channel consistent with our previous work is that under-represented neighborhoods translate directly into an under-representation of Black jurors in the jury pool (Anwar, Bayer, Hjalmarsson (2012)). Though our analysis of zip code racial composition is consistent with such a channel, the lack of juror race in the data prevents definitive conclusions. Another possibility is that individuals who reside in racially and ethnically integrated neighborhoods, regardless of their own race, are less likely to have racial animus towards Black defendants or are better at understanding the context of a potential criminal charge. Regardless of the exact mechanism, our results imply that unequal jury representation results in a substantial legally-unwarranted increase in the severity of punishment for Black defendants in Harris County.

Our paper contributes to the growing literature documenting the extent of unequal jury representation and its consequences. Existing studies focus on representation based on demographic characteristics such as race, age, and gender (Rose, Casarez, Gutierrez (2018)) rather than juror micro-geography (i.e., residential zip code). These studies document that unequal representation generally compounds at each stage of the jury selection process including who: (i) is eligible for jury service, (ii) is included in a court's 'master list' of potential jurors (Hans and Vidmar (1986), Randall, Woods, Martin (2008)), (iii) still resides at the address to which a summons is sent (Fraser (2013)), (iv) responds to the summons (Cohen and Rosales (2007), Fraser (2013), Office of Court Research for Chief Administrative Judge Ann Pfau (2011), Flanagan (2018)) and (v) is seated during pre-trial jury selection (Baldus et al. (2001), Diamond et al. (2009), Noye (2015), DeCamp and DeCamp (2020)). Existing studies have also shown that the under-representation of particular demographic groups, especially Black Americans, can have potentially severe consequences on the racial gap in conviction rates (Anwar, Bayer, Hjalmarsson (2012), Flanagan (2018)); in fact, our earlier research found that

\footnotetext{
${ }^{2}$ An implicit assumption is that additional jurors from each zip code would behave similarly to those currently responding to jury summons; we discuss this assumption further in Section 4.
} 
having just one Black member of the jury pool was sufficient to completely eliminate such a gap in one setting (Anwar, Bayer, Hjalmarsson (2012)). ${ }^{3}$

Our focus on the geography of jury representation is motivated by several practical issues related to remedying unequal jury representation. First, since much of the lack of representation on seated juries is already reflected in jury pools, it is critical that potential remedies address the composition of the pool itself. Policies aimed at addressing aspects of pre-trial jury selection processes are insufficient on their own. Second, demographic and socioeconomic information is typically only collected by the courts at the time of jury service and is not available for all eligible jurors. By contrast, each potential juror's zip code is readily available, making it much easier for courts to measure and rectify unequal neighborhood representation. Finally, eliminating unequal neighborhood representation would likely reduce disparities in many other jury characteristics including race, ethnicity, education, occupation, and income that are likely to be relevant to court outcomes but are not always observed or collected. We return to a discussion of actionable policies that can ensure more equal representation based on juror micro-geography in Section 4.

\section{Background and Data}

Most felony crimes in Texas fall under the jurisdiction of state-level district courts, of which almost every county has its own. There were about 2,400 felony jury trials from June 2005 to March 2012 in the Harris County District Court. ${ }^{4}$ The Harris County District Clerk provided a defendant data set, which includes defendant demographic characteristics (name, race, birth date, gender, zip code of residence), current offense and criminal history characteristics, and verdict and sentencing outcomes. We organized the data at the defendant-case level, so that a defendant with multiple charges that went to the same jury was coded as one observation. This data set did not include information about the jury.

The process of choosing jurors for each trial begins with the master jury list: in Harris County this consists of those individuals in the county who are registered to vote or hold a Texas driver's license or identification card. ${ }^{5}$ Citizens on the list are randomly selected and

\footnotetext{
${ }^{3}$ There is also correlational evidence (Daudistel et al. (1999), Bowers, Steiner, Sandys (2001)) and causal evidence in mock-jury settings (Sommers (2007, 2008), Bielen Marnoff, Macon (forthcoming)) of the jury race-trial outcome relationship. Researchers have also shown that outcomes are affected by other jury characteristics: age (Anwar, Bayer, and Hjalmarsson (2014)), gender (Hoeckstra and Street (2018), Anwar, Bayer, Hjalmarsson (2019a)), political affiliation (Anwar, Bayer, Hjalmarsson (2019b)) and experiences (Philippe and Ouss (2018)).

${ }^{4}$ In 2010, Harris County was the $3^{\text {rd }}$ most populated county in the US, with about half the population living in the city of Houston and half in the surrounding suburbs. Its population was 6\% AAPI, 18\% Non-Hispanic Black, $41 \%$ Hispanic, and 33\% Non-Hispanic white.

${ }^{5}$ See http://www.txcourts.gov/about-texas-courts/juror-information/jury-service-in-texas/.
} 
mailed a summons to report for jury service on a given date. If summoned individuals do not meet eligibility requirements (e.g. age 18, citizen, literate, no prior felonies) or have grounds for an exemption (e.g. older than 70, primary caretaker, attending school), they do not need to appear in court. Eligible individuals who show up for jury duty are randomly assigned to a panel of roughly 65 individuals, which forms the jury pool for a particular trial. Members of the jury pool go through the voir dire process to determine who is seated on the jury (12 members plus 1-4 alternates). Potential jurors can be removed for cause if there is a known reason they cannot be impartial. Prosecutors and defense attorneys can also use peremptory challenges (10 each for a felony trial) to strike potential jurors without providing a reason; though it is illegal for strikes to be based on race or gender, this is difficult to enforce in practice. Thus, while the jury pool is randomly assigned to cases from the set of individuals who report for jury duty, the voir dire process implies the seated jury may be correlated with case and defendant characteristics.

The Harris County District Clerk provided data on the jury pool and seated jury for each felony trial, but not the master list or the summoned list of jurors for a given day. Specifically, the juror demographic data set has the following information for about 300,000 potential jurors who were empaneled for a jury trial (i.e., all who received a summons and showed up at the courthouse): case number, panel identification number, panel status (i.e., on the seated jury, struck, or dismissed), the juror's position in the panel, gender, birth date, and zip code of residence, as well as the dates and times they were assigned to and released from the panel. Notably absent is a direct measure of the juror's race. Using zip code, we merged 2000 Census data on the juror's neighborhood, including the racial composition, median income, population size, high school graduation rate, share with income below poverty, and share foreign born. This is the Census information that would have been available to the courts themselves during the study period.

The descriptive analysis of juror and defendant representation in Section 2 utilizes only these two raw data sets. The analyses of the causal effects of representation on trial outcomes in Sections 3 and 4 necessitate matching the defendant and jury data sets. Our ability to do this match was constrained by incorrect case numbers in the jury data set; the matching procedure described in the online appendix matches $62 \%$ of the trials to jury pools and seated juries. ${ }^{6} \mathrm{We}$ also restrict the sample to cases in which the jury makes both the conviction and sentencing decisions. Texas is one of six states that allow juries to sentence defendants in non-capital cases.

\footnotetext{
${ }^{6} \mathrm{We}$ are highly confident in the quality of these matches. Appendix Table ST1 demonstrates the comparability of the matched and unmatched cases; the only exception is that the matched sample has more female defendant and murder cases, which we tried more aggressively to match.
} 
Before seeing the jury pool, the defendant must decide whether they want a trial by jury and who will do the sentencing upon conviction (judge or jury). The same jury decides both convictions and sanctions (Weninger (1994)). These restrictions yield 981 non-capital felony trials with matched jury data.

In $75 \%$ of these trials, the defendant is eligible for a life sentence; the court equates such a sentence to 99 years in prison. As described in the Texas statutes, minimum sentences for these cases depend on the defendant's criminal history and can be as low as five years (e.g. if convicted of a $1^{\text {st }}$ degree felony with no history). ${ }^{7}$ Our analysis in Sections 3 and 4 focuses on the 734 life-sentence eligible cases, which constitutes the majority of our sample and allow juries the most discretion in sentencing decisions. Summary statistics for these life sentenceeligible cases are shown in Appendix Table ST2. About 59\%, 26\% and 14\% of defendants are classified as Black, Hispanic, and white respectively; just $6 \%$ are female. The distribution of charges is heavily skewed towards serious violent offenses $(28 \%$ and $24 \%$ of cases include a murder and robbery charge, respectively) and sex offenses (19\% of cases), consistent with this being a life-sentence eligible sample. We consider two main trial outcomes. The first is whether a defendant is convicted of a life sentence (versus either an acquittal or a sentence of less than 99 years); about $15 \%$ of our sample is convicted of a life sentence. The second is the sentence length (in years) the jury assigns, where we code acquittals as a sentence of zero years to avoid conditioning the sentencing decision on the selection of guilty verdicts. Using this measure, the average sentence length in our sample is almost 39 years. Given concerns about the top-coding of life sentences by the Texas courts as 99 years, Section 3 includes a number of sensitivity tests to show that the coding of life sentences is not driving our findings.

\section{Geographic Representation in the Jury Pool, Seated Jury, and Defendant Population}

This section measures the extent to which individuals from various neighborhoods (zip codes) are over- or under-represented in two populations at the core of the justice system: the jury pool that decides case outcomes and the defendants subject to these decisions. Defining neighborhoods based on zip codes is consistent with the role played by zip code in jury software systems; this is one of the few juror variables systematically recorded in Harris County. ${ }^{8} \mathrm{We}$ calculate jury and defendant representation ratios for the sample of 299,945 jury pool members

\footnotetext{
${ }^{7}$ See http://www.statutes.legis.state.tx.us/Docs/PE/htm/PE.12.htm.

${ }^{8}$ Zip code has also been highlighted as relevant in other jurisdictions. There are anecdotes in which zip codes were inadvertently excluded from receiving summons due to software flaws (Chernoff (2016)). Other jurisdictions, e.g. Philadelphia, have investigated how low summons response rates map to zip codes (First Judicial District of Pennsylvania (2018)).
} 
and 1,754 defendants (with observable zip code information) from 129 Harris County zip codes. Equation (1) demonstrates how the jury pool ratio is calculated. Specifically, for each zip code $z$, we calculate the ratio between the share of all individuals in the pooled sample of jury pools $(\mathrm{N}=299,945)$ from zip code $z$ and the share of the population (over age 16) in the census from zip code $z$. This ratio will be greater (less) than one for zip codes that are over (under)represented in the jury pool relative to the census. We follow the same procedure to create representation ratios for defendants and seated jurors.

$$
\text { Representation }_{z}^{\text {pool }}=\frac{\left(\text { Njurypool }_{z} / \sum_{z=1}^{Z} \text { Njurypool }_{z}\right)}{\left(\text { Ncensus }_{Z} / \sum_{Z=1}^{Z} \text { Ncensus }_{Z}\right)}
$$

A conceptual issue arises in the choice of measure to use for the denominator of the representation ratio: who should be included given that jurors are supposed to reflect a fair cross section of the community? A reasonable case might be made for including the full population or only adults, citizens, eligible jurors, or those on the court's master list. Absent clear legal guidance and given available data, we base our primary measure on the adult population, while also assessing robustness to using the full population. ${ }^{9}$

The introduction of this novel measure of representation based on micro-geography (zip code) is an important contribution of our paper. To date, jury scholars (including us) have generally focused on measures of the representation of a particular demographic group in an entire jurisdiction. ${ }^{10}$ In one sense, our measure simply captures a new dimension of representation based on residential geography. But geographic representation has two additional advantages. First, as we show for Harris County, residential geography is typically strongly correlated with many other variables - e.g., race, ethnicity, employment, education, income - that may be important for court outcomes. Thus, juror zip code summarizes many dimensions of representation in a single measure. Second, unlike many demographic and socioeconomic variables, zip code is available for every potential juror in every court in the

\footnotetext{
9 The distribution of the representation ratio is almost identical when using the total population rather than the adult population. In fact, over $90 \%$ of zip codes would be classified into the same quartile of this distribution regardless of the population measure used in the denominator. This is important as these quartiles are the main measures used in our regressions.

${ }^{10}$ Two main measures are used in the literature: absolute disparity (e.g. proportion in jury pool minus proportion in population) and comparative disparity (e.g. absolute disparity divided by proportion in population). See Rose, Casarez, and Gutierrez (2018).
} 
country. This makes it feasible for courts to examine whether certain neighborhoods are systematically over- or under-represented on juries and suggests straightforward remedies.

Our analysis of jury and defendant representation reveals four key results. First, Panel A of Figure 1 shows that many zip codes have jury pool representation ratios far from one. In fact, $25 \%$ have ratios less than 0.61 and $25 \%$ have ratios greater than 1.39. Panel 1A of Figure 2 plots these ratios in a map of Harris County zip codes, revealing that the over-represented zip codes (shaded darker) are in the outskirts or suburbs. Unfortunately, our data do not allow us to directly investigate the relative importance of the various potential sources (e.g. the master list, eligibility criteria, returned summons, non-response) of disproportionate representation in the pool. A 2013 Houston Chronicle article suggests that multiple sources are important, reporting that less than $33 \%$ of summoned jurors in Harris County show up for jury duty; more than $35 \%$ do not respond at all and $20 \%$ of summons are returned as undeliverable (Fraser (2013)). ${ }^{11}$

Second, Panel B of Figure 1 shows that the wide dispersion in jury representation ratios originates in the jury pool itself and not the process through which the seated jury is selected. This result implies that remedies designed to ensure fair representation must focus not only on the voir dire process used to select jurors but, importantly, on the system used to develop the jury pool.

Third, certain zip codes are severely over- and under-represented amongst the defendant population as well. However, Panel 1B of Figure 2 shows that the same zip codes that are underrepresented in the jury pool are over-represented amongst defendants and vice versa.

Fourth, zip code representation in the jury pool is closely related to other zip code characteristics. Panels 1C and 1D of Figure 2 highlight the differential racial composition of these zip codes. It is clear from visual inspection that the most represented zip codes in the jury pool also have the highest proportion of white residents, while those most represented amongst defendants have the highest fraction of Black residents. Table 1 demonstrates the starkness of this contrast (e.g., on average, $26.3 \%$ and $10.1 \%$ of the population is Black in the under- and over-represented zip codes, respectively) and that race is not the only dimension in which these neighborhoods differ. Under-represented areas have more than twice as many Hispanic residents, 50\% lower median income, three times as many residents in poverty, higher unemployment rates, lower educational attainment, and more foreign-born residents than overrepresented neighborhoods.

\footnotetext{
${ }^{11}$ These statistics are not unique to Harris County. A report on Philadelphia highlights that it is not uncommon "to mail out 1800-2000 summonses in order to have 500-600 jurors report for service" (First Judicial District of Pennsylvania (2018)).
} 


\section{The Causal Effect of Unequal Representation on Trial Outcomes}

We now investigate the impact of jury pool representation on trial outcomes using the matched jury pool-defendant data. Our research design parallels that used in our earlier work studying the effect of jury race on felony convictions in Florida (Anwar, Bayer, Hjalmarsson (2012)) and is motivated by the quasi-random way in which jury pools are assigned to trials. Specifically, the approximately 65 individuals who constitute the jury pool for a given trial are randomly assigned to a trial after having been randomly called for jury duty on a given day. The only aspect of the process that is not completely random is the choice of individual jurors to respond to a jury summons. These choices would only create a problem for our analysis if they were somehow systematically correlated with case and defendant characteristics. Appendix Tables ST3 and ST4 demonstrate that jury pools are effectively randomly assigned by regressing jury pool characteristics (representation ratios in ST3 and gender, age, and zip code characteristics in ST4) on 14 defendant and case characteristics. If the jury pool were truly randomly assigned to cases, the coefficients would be close to zero and statistically insignificant. This is what we find: only 5 (16) of the 168 coefficients are significant at the 5\% (10\%) levels and F-tests that jointly determine whether all coefficients equal zero are insignificant in each regression.

Given daily fluctuations in the jury pool, the geographic distribution of the neighborhoods of potential jurors varies across trials. By isolating this quasi-random variation, we can identify the causal impact of jurors from different neighborhoods on trial outcomes. Though these institutional features ensure that the jury pool is effectively randomly assigned, the voir dire process implies that the seated jury is not; we therefore cannot identify the causal effect of the seated jury itself.

Table 2 presents the results of regressing trial outcomes (sentence length in columns (1) - (4) and conviction of a life sentence in columns (5)-(6)) on the proportion of the jury pool from the first and fourth quartiles of the distribution of representation ratios among jury pool members, where the reference group includes those in quartiles two and three. Jurors in the fourth quartile consist of the $25 \%$ of jury pool members that come from zip codes with the highest representation ratios. ${ }^{12}$ The results are presented separately for the sub-samples of white and Black defendants. Results for Hispanic defendants are included in Appendix Table ST5. These results indicate that the impact of increasing the share of jurors from the fourth quartile

\footnotetext{
${ }^{12}$ These quartile cutoffs were defined with the full jury pool sample used for the analysis in Section 2. The proportion of jurors in a given pool from the fourth quartile ranges from .15 to .35 .
} 
on the length of sentences Black defendants receive is strong and statistically significant. This significant effect is seen in both the entire sample of matched cases and the analysis sample of life-sentence eligible cases, though the effects in the life-sentence eligible cases are larger. Given concerns about the sensitivity of these results to the fact that Texas codes life sentences as 99 years, we emphasize that Table 2 shows that more jurors from the fourth quartile also significantly increases the extensive margin chance of conviction for a life sentence. Furthermore, Appendix Table ST6 demonstrates that this $4^{\text {th }}$ quartile effect on Black defendants is robust to how sentence length is measured (in logs, recoding sentences to be truncated when the individual reaches age 90, or the sentence length upon first eligibility for parole) and is not just observed at the mean of the sentence length distribution, but also at the median and some higher percentiles $\left(70^{\text {th }}\right.$ and $\left.80^{\text {th }}\right)$. Though point estimates indicate that white defendants receive somewhat longer sentences when a higher fraction of the jury pool comes from zip codes in the first quartile of the representation index distribution, these results are not statistically significant. Similarly, no significant effects are seen for Hispanic defendants.

As highlighted in Table 1, over-represented neighborhoods have a higher proportion of white, high-income, highly educated, and US-born residents. Appendix Table ST7 investigates whether each of these characteristics is associated with sentence severity by regressing whether an individual was convicted of a life sentence on controls for the composition of the jury pool, including age, gender, and neighborhood racial composition and, in successive columns, neighborhood measures of median family income, percentage of high school graduates and percentage foreign born. Appendix Table ST7 controls for zip code race using the fraction of the jury pool that resides in zip codes that are at least 76 percent white (a quarter of jury pool members meet this criterion). Appendix Table ST8 presents results for alternative measures of neighborhood racial composition as well as specifications using sentence length as the outcome. As results are somewhat sensitive to specification, we view them as only suggestive.

The results suggest that sentencing outcomes for Black defendants are worse (a life sentence is more likely) when jury pool members are from disproportionately white neighborhoods while sentencing outcomes are better (shorter) when jury pool members come from disproportionately Black neighborhoods. As these coefficients lose significance (but remain large) when other neighborhood controls are included, we cannot definitively conclude whether it is neighborhood race or correlates of race that matter. ${ }^{13}$ Importantly, as discussed in the introduction, several distinct channels might explain why neighborhood racial composition

\footnotetext{
${ }^{13}$ There appears to be a positive relationship between the fraction of foreign-born residents and sentence length for white defendants.
} 
appears to matter. Increased representation from racially and ethnically integrated zip codes in Houston, for instance, might affect outcomes either by increasing Black representation on juries or because residents of these neighborhoods have different perspectives than their suburban counterparts, regardless of their own race or ethnicity.

\section{Simulating Equal Representation and Policy Discussion}

Section 3 showed that having a higher concentration of jurors in the pool from overrepresented zip codes significantly impacts sentence lengths for Black defendants. This section assesses the magnitude of these effects by simulating how sentences would change if residents from Harris County neighborhoods were equally represented in jury pools. We conclude by linking these findings to a discussion of potential policy reforms that could be used to achieve such equal neighborhood representation.

We simulate the average sentence length for defendants under equal jury representation in two steps. First, we estimate equation (2), which relates the sentence length to the proportion of members of the jury pool in each quartile of the zip code representation distribution.

$$
\begin{aligned}
& \text { Sentence Length }{ }_{i}=\beta_{1} * \text { Proportion_Quartile } 1_{i}+\beta_{2} * \text { Proportion_Quartile } 2_{i}+ \\
& \beta_{3} * \text { Proportion_Quartile } 3_{i}+\beta_{4} * \text { Proportion_Quartile }_{i}+\varepsilon_{\mathrm{i}}
\end{aligned}
$$

We then use the resulting estimated coefficients to predict average sentences for Black and white defendants if the proportion of jury pool members from each quartile reflected the proportion of the Harris County population (over age 16) that actually resides in the neighborhoods within the respective quartile. In particular, while the proportion of the jury pool that comes from the zip codes in each quartile is 0.25 (by construction), the proportions of the jury pool that should come from zip codes in the quartile 1 through 4 bins are: $0.46,0.24,0.18$, and 0.12 , respectively. Adjusting these values provides an estimate of what sentence lengths would be if the jury pool accurately reflected the distribution of the Harris County population across neighborhoods and all jurors from each zip code behave similarly to those we observe responding to jury summons. Whether or not the latter assumption is satisfied may depend on the type of policy used to achieve neighborhood representation; we return to this discussion after presenting the simulation results.

We extend this initial simulation in two key ways. First, we increase the number of bins used to group zip codes from the initial four quantiles to 19 evenly spaced intervals of the representation ratio index. This approach more effectively re-weights zip codes so that the 
simulated representation ratio is close to one for each neighborhood. ${ }^{14}$ Second, in addition to examining simulated changes in average sentence length, we also consider how equal representation would change both the proportion of defendants convicted of a life sentence (using a logit model) and the median and $75^{\text {th }}$ quantiles of sentence length (using quantile regressions). We look at these outcomes to gauge the extent to which the likelihood of receiving a life sentence drives the results for average sentence length.

The simulation results are presented in Table 3. Each row corresponds to a different simulation for white or Black defendants, varying the number of bins in which zip codes are grouped (4 versus 19) and the outcome parameter simulated. The first two columns show a comparison between the actual value of the parameter of interest and that predicted by the model - i.e., the fitted value using the proportion of the jury pool that comes in a given representation bin in the data. In all cases, the model produces estimates that are close to the actual values. The next column presents the simulated results when the proportions are adjusted to zip code population shares.

The results for Black defendants are striking. If the jury pool was reflective of the county, the average sentence would fall by almost 15 years (using the 19-bin specification), and the median sentence length would essentially be cut in half, from 31.5 to 16 years. The likelihood Black defendants would be convicted of a life sentence would also fall by more than 50 percent. The magnitudes of these reductions in sentence length under equal representation are substantial precisely because they sharply reduce the proportion of jurors from quartile 4 neighborhoods, who are particularly harmful to Black defendants. The simulation results for white defendants generally indicate that they would have longer sentences if juries were more representative, although these impacts are never close to statistically significant (potentially due to the limited sample size).

Addressing the unrepresentativeness of jury pools can have important consequences for fairness that extend beyond what happens directly in jury trials. While only a small fraction of criminal cases make it to a jury trial, expected trial outcomes can impact the earlier stages of

\footnotetext{
${ }^{14}$ In general, the binning of neighborhood zip codes into quartile bins helps mitigate any generic measurement error in the representation ratio for each zip code. The fact that the results are similar regardless of whether we use 4 quartile bins or 19 evenly space intervals suggests generic measurement error is not a major issue. A more systematic issue might arise, however, because our population counts are from the year 2000, leading to an overstatement of over-representation for rapidly growing zip codes, especially late in the study period. This issue has a limited impact on interpretation of the causal analysis - i.e., it does not change the conclusion that jurors from the particular zip codes in the $4^{\text {th }}$ quartile bin are significantly more punitive for Black defendants. It does, however, potentially affect the simulations presented here because the adjustment needed to ensure equal representation would be smaller for these rapidly growing zip codes. As a result, we view these simulations as providing an upper bound on the impact of equalizing representation.
} 
the criminal justice process, affecting prosecutors' decisions to bring cases forward and the potential plea deals that each side is willing to accept (Spohn et al. (2002)).

A number of potential policy remedies are available to mitigate the racial disparities in outcomes attributable to unequal neighborhood representation. The effectiveness of each measure will depend on why certain neighborhoods are under-represented and the extent to which the policy affects the composition of jurors drawn from each neighborhood. Unequal representation in the jury pool can arise via unequal representation in the source list itself or non-response due to: (i) undelivered summons, (ii) court-sanctioned reasons (such as having a criminal record or being the sole care-giver of a small child), and (iii) an active choice, which could, for instance, arise out of not being able to miss work (due to both job-security or income related issues), as well as due to a general distrust of the justice system (First Judicial District of Pennsylvania (2018)).

We begin the policy discussion with the first potential channel - the source lists. Texas currently only includes residents who have registered to vote or who have a state driver's license or identification card. Though these are by far the most common mandated source lists across states, a number of states permit courts to supplement the master list with additional sources (e.g. lists of utility subscribers, taxpayers, and those receiving government benefits) that are more likely to include under-represented populations (Mize, Hannaford-Agor, Waters (2007)). Outside of the jury system, policies that make it easier to register to vote would also help broaden the source list.

Expanded source lists can only do so much if non-response is large and markedly unequal across neighborhoods and populations. As highlighted earlier, this is indeed the case in Houston. One recognized source of undelivered summons is out-of-date addresses, which more frequent updating of source lists would help alleviate. Jurisdictions could also attempt to deal with selective non-response via informational campaigns and by providing substantially higher jury duty payments.

Policies that expand source lists or increase response rates are likely to change the composition of jurors drawn from neighborhoods that are currently under-represented. Thus, equalizing representation through these channels could potentially lead to different results than estimated in our simulations (which implicitly assume marginal juror behavior would not change). Importantly, it is possible that such policies could reduce racial disparities in sentencing even more than estimated above, if newly added jurors help make jury pools more representative of the community in terms of racial and socioeconomic composition or are systematically less trusting of law enforcement or the justice system. 
Finally, a straightforward way to ensure a balanced distribution of jurors across neighborhoods, and one that is closely aligned with the analysis presented here, would be to oversample residents from under-represented neighborhoods when sending jury summons. Assuming that response rates do not change when over-sampling, this policy would have little effect on the marginal juror and the simulation results above should be an accurate representation of the impact of such a policy. An attractive feature of this remedy is that it equalizes representation across neighborhoods regardless of the underlying reason for any existing unequal representation. A handful of jurisdictions have implemented this kind of sampling policy at a relatively low administrative cost (Orlando and Chen (2020)). ${ }^{15}$ In order not to overburden those jurors from under-represented zip codes who are already serving on juries, these oversampling policies are best implemented in tandem with the policies mentioned above that aim to deepen the available pool in a given zip code.

\section{Conclusion}

While legally required to reflect a fair cross section of the community, juries across the United States are often highly unrepresentative along many dimensions of demography and socioeconomic status. The vast majority of American courts currently do little to remedy this failure, in part because of the cost and complexities of measuring jury representation and rectifying the problem.

This study was motivated by the potential for a new measure of representation based on juror micro-geography (zip code) to provide a practical tool for courts to use in evaluating and addressing unequal jury representation. Using detailed data from Harris County, Texas, we showed that residents of high income, predominantly white suburban zip codes are substantially over-represented on juries and that this has a substantial negative effect on trial outcomes for Black defendants. Equalizing jury representation across neighborhoods would substantially reduce these legally unwarranted racial disparities in conviction rates and sentencing.

Importantly, because residential zip code is readily available for every potential juror in every court in the country, it should be straightforward for courts to evaluate whether their jury pools and seated juries currently reflect a fair geographic representation of their local communities. And many potential remedies can be used to ensure more equal representation including broadening jury eligibility, expanding the source lists used for jury summons, policies that increase response rates to jury summons, and over-sampling potential jurors from under-

\footnotetext{
${ }^{15}$ These jurisdictions typically send a new summons to another juror from the same zip code whenever an initial summons is returned as undeliverable or not responded to within a given time period.
} 
represented zip codes when sending jury summons. Ensuring that juries are geographically representative of their communities would make jury trials fundamentally fairer throughout the country and bring the courts in line with this basic requirement of the U.S. legal code.

\section{References}

1. Anwar, Shamena, Patrick Bayer, and Randi Hjalmarsson. 2012. "The Impact of Jury Race in Criminal Trials." Quarterly Journal of Economics 127: 1017-1055.

2. Anwar, Shamena, Patrick Bayer, and Randi Hjalmarsson. 2014. "The Role of Age in Jury Selection and Trial Outcomes." Journal of Law and Economics 57(4): 1001-1030.

3. Anwar, Shamena, Patrick Bayer, and Randi Hjalmarsson. 2019a. "A Jury of Her Peers: The Impact of the First Female Jurors on Criminal Verdicts." The Economic Journal 129: 603-650.

4. Anwar, Shamena, Patrick Bayer and Randi Hjalmarsson. 2019b. "Politics in the Courtroom: Political Ideology and Jury Decision Making." Journal of the European Economic Association 17(3): 835-875

5. Anwar, Shamena, Patrick Bayer and Randi Hjalmarsson. 2021. "Replication Data and Code for: Unequal Jury Representation and Its Consequences." American Economic Association [publisher], Inter-university Consortium for Political and Social Research [distributor], openicpsr-147441.

6. Baldus, David C., George Woodworth, David Zuckerman, Neil Alan Weiner, and Barbara Broffitt. 2001." The Use of Peremptory Challenges in Capital Murder Trials: A Legal and Empirical Analysis." University of Pennsylvania Journal of Constitutional Law 3:3-169.

7. Bielen, Samantha, Wim Marneffe, and Naci Mocan. Forthcoming. "Racial Bias and Ingroup Bias: Evidence from Virtual Reality Courtrooms." Journal of Law and Economics.

8. Bowers, W.J, B.D Steiner, and M. Sandys. 2001. "Death Sentencing in Black and White: An Empirical Analysis of Jurors' Race and Jury Racial Composition." University of Pennsylvania Journal of Constitutional Law 3: 171-275.

9. Chernoff, Nina. 2016. "No Records, No Right: Discovery \& the Fair Cross-Section Guarantee." Iowa Law Review 101: 1719- 1785.

10. Cohen, Bob and Janet Rosales. 2007. "Racial and Ethnic Disparity in Manhattan Jury Pools: Results of a Survey and Suggestions for Reform." Citizen Action of New York.

11. Daudistel, H. C., H.M. Hosch, M.D. Holmes, and J.B. Graves. 1999. "Effects of Defendant Ethnicity on Juries' Dispositions of Felony Cases." Journal of Applied Social Psychology, 29: 317-336.

12. DeCamp, Whitney and Elise DeCamp. 2020. "It's Still about Race. Peremptory Challenge Use on Black Prospective Jurors." Journal of Research in Crime and Delinquency 57(1): 3-30.

13. Diamond, Shari Seidman, Destiny Peery, Francis J. Dolan, and Emily Dolan. 2009. "Achieving Diversity on the Jury: Jury Size and the Peremptory Challenge." Journal of Empirical Legal Studies 6:425-49. 
14. First Judicial District of Pennsylvania. 2018. "FJD Juror Participation Initiative." accessed from https://www.courts.phila.gov/pdf/report/FJD_JPIC_Final.pdf.

15. Flanagan, Fran. 2018. "Race, Gender, and Juries: Evidence from North Carolina.” Journal of Law and Economics 61(2):189-214.

16. Fraser, Jayme. 2013. "Only a Third of Those Summoned for Jury Duty Show Up" Houston Chronicle. Dec 4, 2013.

17. Hans, Valerie and Neil Vidmar. 1986. Judging the Jury. Perseus Publishing.

18. Hoekstra, Mark and Brittany Street. 2018. "The Effect of Own-Gender Jurors on Conviction Rates." NBER Working Paper 25013, September.

19. Mize, Gregory, Paula Hannaford-Agor, and Nicole Waters. 2007. "The State-of-the States Survey of Jury Improvement Efforts: A Compendium Report." National Center for State Courts and State Justice Institute.

20. Noye, Ursula. 2015. "Blackstrikes: A Study of the Racially Disparate Use of Peremptory Challenges by the Caddo Parish District Attorney's Office." Reprieve Australia. Accessed from

www.prisonpolicy.org/scans/reprieve_australia/Blackstrikes_Caddo_Parish_August_2015 .pdf

21. Office of Court Research for Chief Administrative Judge Ann Pfau. 2011. "Jury Representativeness: A Demographic Study of Juror Qualification and Summoning in Monroe County, New York."

22. Orlando, James and Duke Chen. 2020. "Jury Pools and Fair Cross Section Requirement." Office of Legislative Research, 2020-R-0299. Accessed from https://www.cga.ct.gov/2020/rpt/pdf/2020-R-0299.pdf.

23. Philippe, Arnaud and Aurelie Ouss. 2018. "No Hatred or Malice, Fear or Affection": Media and Sentencing." Journal of Political Economy 126: 2134-78.

24. Randall, Ronald, James Woods and Robert Martin. 2008. "Racial Representativeness of Juries: An Analysis of Source List and Administrative Effects on the Jury Pool" The Justice System Journal 29(1): 71-84.

25. Rose, Mary, Raul Casarez, and Carmen Gutierrez. 2018. "Jury Pool Underrepresentation in the Modern Era: Evidence from Federal Courts." Journal of Empirical Legal Studies 15(2): 378-405.

26. Sommers, Samuel. 2007. "Race and the Decision Making of Juries." Legal and Criminological Psychology 12: 171-187.

27. Sommers, Samuel. 2008. "Determinants and Consequences of Jury Racial Diversity: Empirical Findings, Implications, and Directions for Future Research.” Social Issues and Policy Review, 2: 65-102.

28. Spohn, Cassia, Dawn Beichner, Erika Frenzel, and David Holleran. 2002. "Prosecutors' Charging Decisions in Sexual Assault Cases: A Multi-Site Study, Final Report." Accessed from https://www.ncjrs.gov/pdffiles1/nij/grants/197048.pdf.

29. Weninger, Robert A.. 1994. "Jury Sentencing in Noncapital Cases: A Case Study of El Paso County, Texas." Washington University Journal Urban \& Contemporary Law, 45. 
Figure 1. Distribution of the Zip Code Representation Ratio

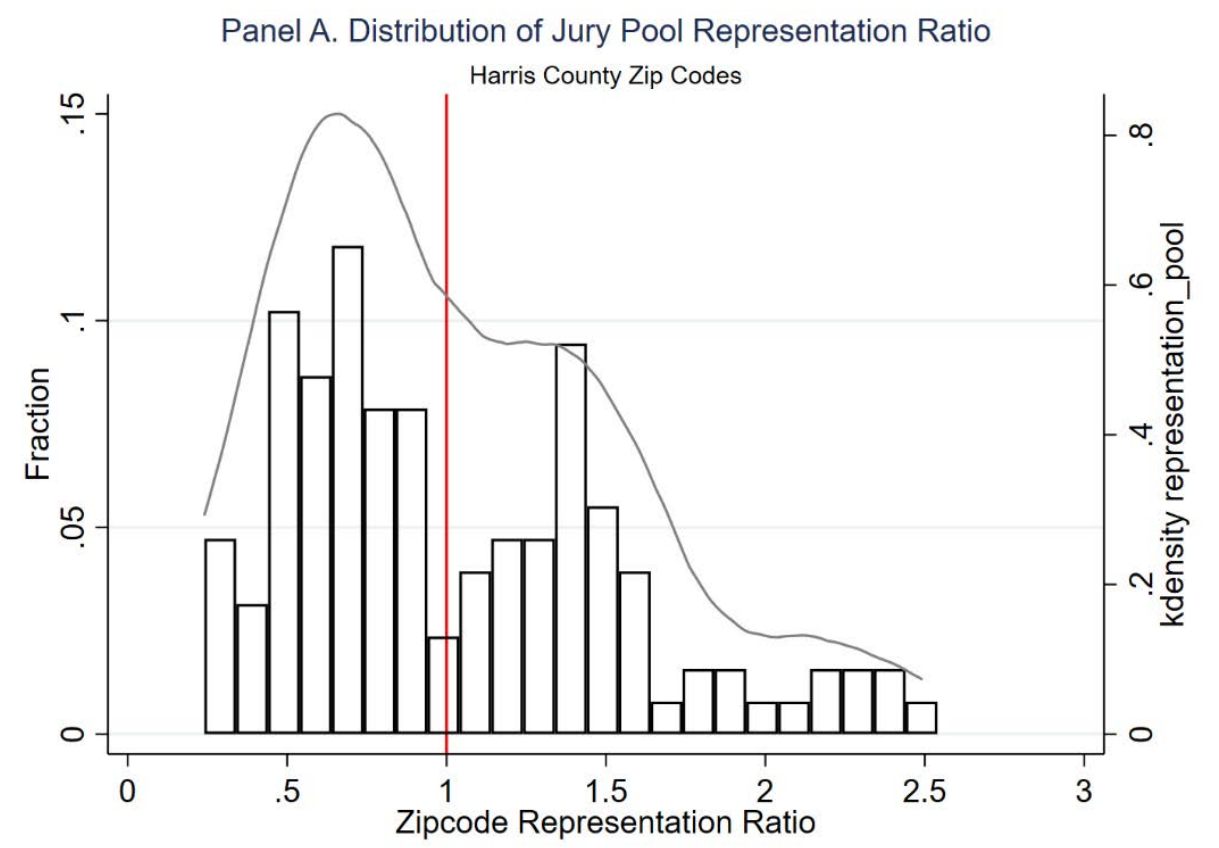

Panel B. Distribution of Zip Code Representation Ratio: Jury Pool vs. Seated Jurors

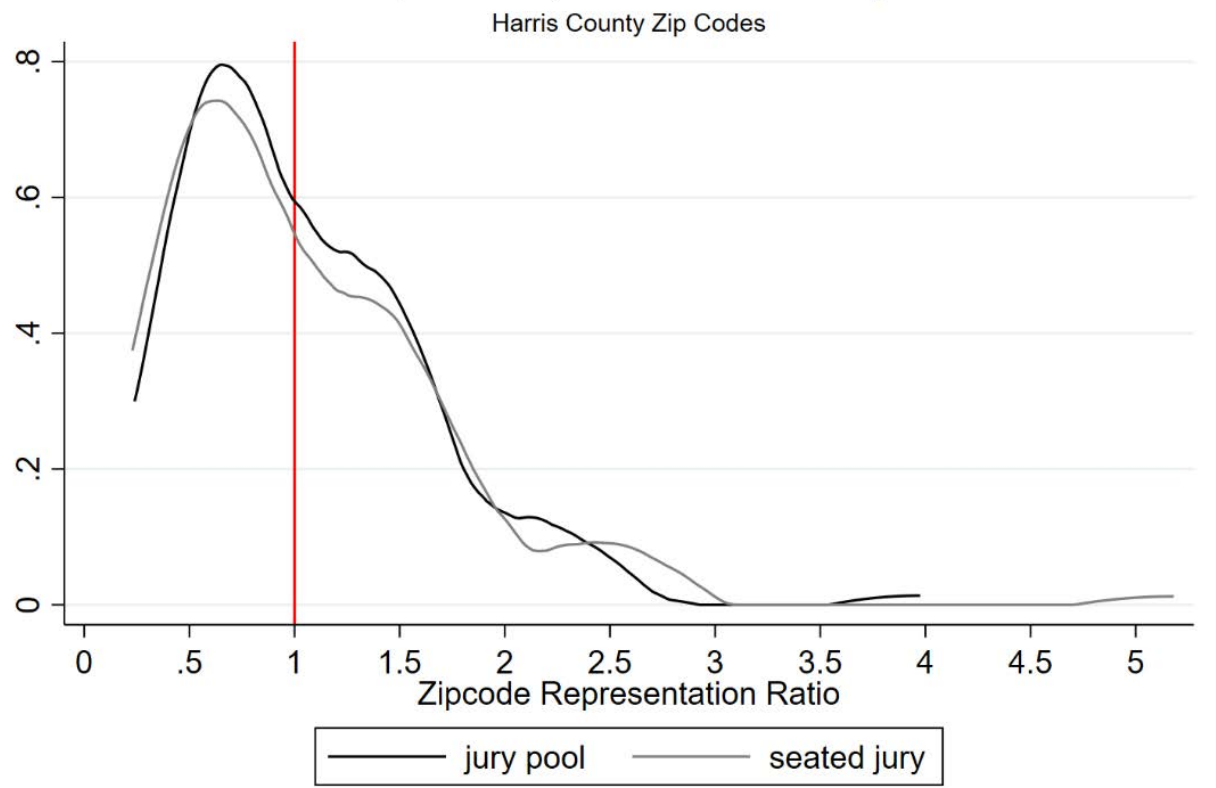

Note - Panel A plots the distribution (histogram on the left axis and kernel density on the right) of the representation ratio for zip codes in the Harris County jury pool data. Panel B plots kernel densities of the distribution of zip code representation in the jury pool (black line) and seated jury (gray line). The seated jury information is based on the raw data provided from Harris County, with the caveat that there is some measurement error in classifying individuals as seated. In both figures, ratios less than one are under-represented relative to the census. Truncation on the X-axis excludes two zip codes from Panel A and one zip code from B. 
Figure 2. Harris County Maps of Zip code Race and Representation in Jury Pools and Defendant Populations

Panel A. Jury Pool Representation Ratio

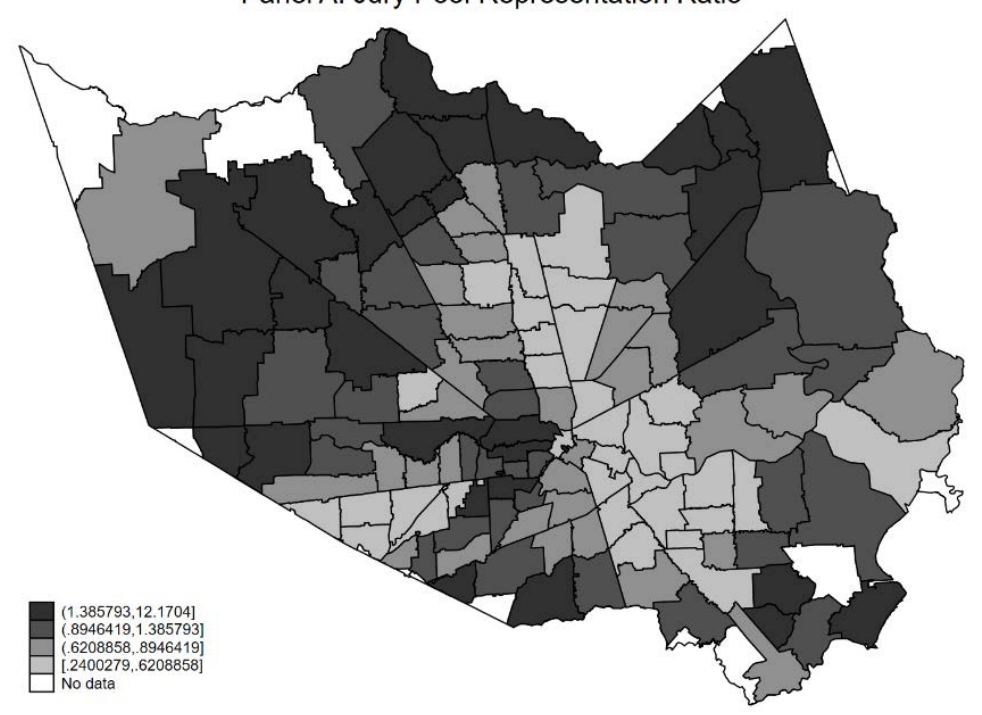

Panel C. Zip Code \% White

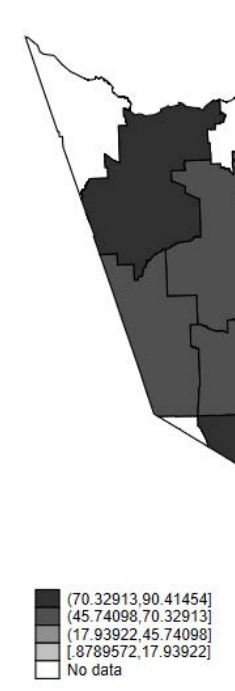

\section{Panel C. Zip Code \% White} te-
Note -- Panels $1 \mathrm{~A}-1$

Panels A and B present resent maps of Harris County zip codes; shape files obtained from https://koordinates.com/layer/97880-harris-county-tx-zipcodes/ . according to the 2000 Census. In all figures, zip codes are broken down into quartiles, darker shading corresponds to higher values. These descriptive zip code quartiles do not perfectly match the quartile cutoffs defined in the main analysis, which are based on the entire sample of potential jurors (rather than aggregating those to the zip code level).
Panel B. Defendant Representation Ratio

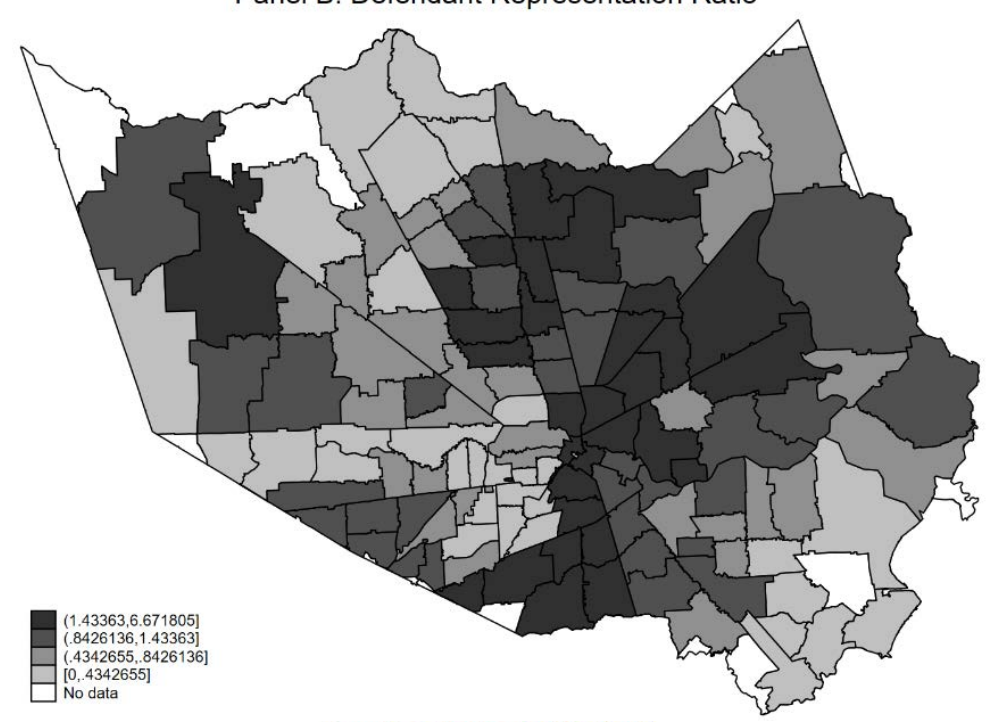

Panel D. Zip Code \% Black

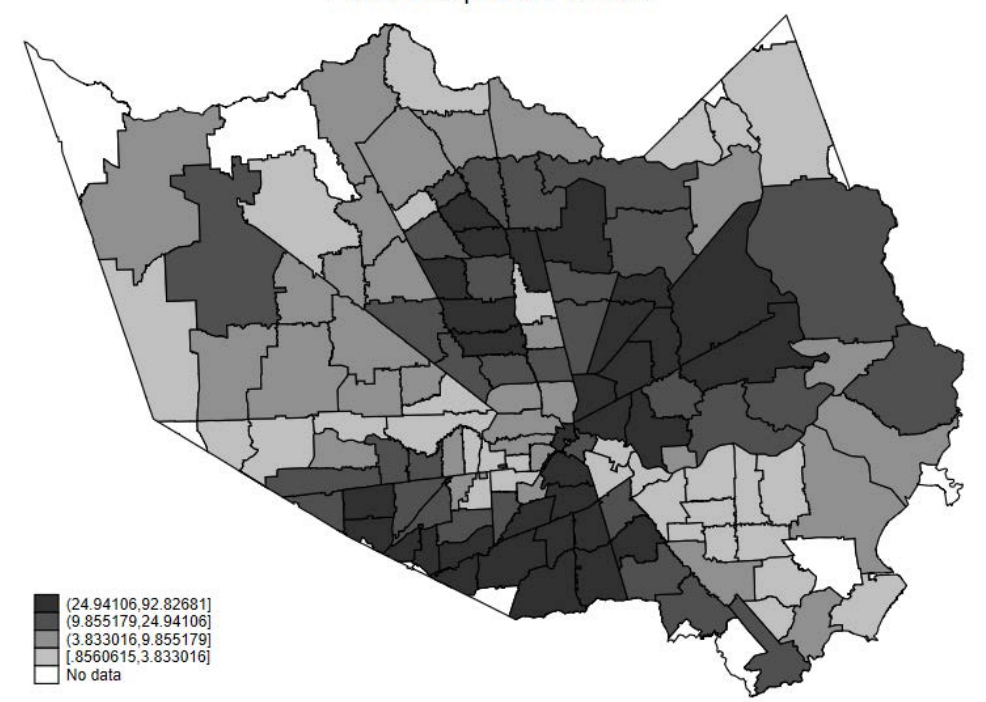


Table 1. Census Characteristics of Zip Codes Under- and Over-Represented in Harris County Jury Pool

\begin{tabular}{|c|c|c|c|c|}
\hline \multirow[b]{2}{*}{ zip code measure } & \multicolumn{2}{|c|}{$\begin{array}{c}\text { Underrepresented }(<1) \\
\mathrm{N}=71 \text { zip codes }\end{array}$} & \multicolumn{2}{|c|}{$\begin{array}{c}\text { Overrepresented }(>1) \\
\mathrm{N}=58 \text { zip codes }\end{array}$} \\
\hline & Mean & SD & Mean & SD \\
\hline pool representation ratio & 0.6 & 0.2 & 1.8 & 1.5 \\
\hline$\%$ white & 26.4 & 20.6 & 64.8 & 19.4 \\
\hline$\%$ black & 26.3 & 25.0 & 10.1 & 13.0 \\
\hline$\%$ hispanic & 42.0 & 23.0 & 18.4 & 11.0 \\
\hline$\%$ labor force (over 16) & 61.1 & 9.8 & 70.0 & 5.4 \\
\hline zip code median family income & 38238.9 & 11574.6 & 76572.7 & 30282.9 \\
\hline$\%$ income $<$ poverty & 17.7 & 8.3 & 5.6 & 3.9 \\
\hline$\%$ high school graduates & 63.8 & 15.9 & 87.5 & 9.3 \\
\hline$\%$ foreign born & 25.0 & 12.4 & 14.3 & 6.7 \\
\hline total population in zip & 29602.9 & 13740.5 & 24413.3 & 12956.8 \\
\hline population $>$ age 16 & 20984.7 & 9612.0 & 17893.1 & 9107.5 \\
\hline
\end{tabular}

Note - Zip codes are classified as under- and over-represented based on their representation in the raw jury pool data relative to that in the census. 
Table 2: Relationship Between Jury Pool Representation and Trial Outcomes

\begin{tabular}{|c|c|c|c|c|c|c|}
\hline & \multicolumn{4}{|c|}{ Sentence Length (years w/acquittals=0) } & \multicolumn{2}{|c|}{ Convicted of a Life Sentence } \\
\hline & (1) & $(2)$ & (3) & (4) & $(5)$ & $(6)$ \\
\hline Proportion of Pool in Q1 & $\begin{array}{c}21.15 \\
(52.52)\end{array}$ & $\begin{array}{c}1.506 \\
(25.75)\end{array}$ & $\begin{array}{c}38.25 \\
(68.85)\end{array}$ & $\begin{array}{c}3.229 \\
(29.13)\end{array}$ & $\begin{array}{r}-0.0283 \\
(0.793)\end{array}$ & $\begin{array}{l}0.0161 \\
(0.310)\end{array}$ \\
\hline Proportion of Pool in Q4 & $\begin{array}{l}-14.20 \\
(46.23)\end{array}$ & $\begin{array}{c}59.45 * * \\
(25.24)\end{array}$ & $\begin{array}{c}35.91 \\
(62.00)\end{array}$ & $\begin{array}{c}92.06 * * * \\
(29.36)\end{array}$ & $\begin{array}{l}-0.275 \\
(0.714)\end{array}$ & $\begin{array}{c}0.884 * * * \\
(0.313)\end{array}$ \\
\hline Constant & $\begin{array}{c}28.03 \\
(20.59)\end{array}$ & $\begin{array}{c}15.62 \\
(10.97)\end{array}$ & $\begin{array}{c}23.06 \\
(26.89) \\
\end{array}$ & $\begin{array}{c}12.64 \\
(12.63) \\
\end{array}$ & $\begin{array}{c}0.269 \\
(0.309) \\
\end{array}$ & $\begin{array}{l}-0.0996 \\
(0.135)\end{array}$ \\
\hline Full Sample or Life Sent. Elig. (LSE)? & Full & Full & LSE & LSE & LSE & LSE \\
\hline Defendant Race & White & Black & White & Black & White & Black \\
\hline Observations & 166 & 551 & 104 & 436 & 104 & 436 \\
\hline R-Squared & 0.003 & 0.012 & 0.005 & 0.026 & 0.002 & 0.022 \\
\hline
\end{tabular}


Table 3: What Would Trial Outcomes be if the Jury Pool was Representative of Harris County?

\begin{tabular}{|c|c|c|c|c|c|}
\hline & Parameter & Actual Value & $\begin{array}{c}\text { Estimated } \\
\text { Actual Value }\end{array}$ & $\begin{array}{c}\text { Simulated Value } \\
\text { where Jury Pool } \\
\text { Reflective of } \\
\text { Population } \\
\end{array}$ & $\begin{array}{c}\text { p-value } \\
(\text { simulated } \neq \\
\text { estimated actual }) \\
\end{array}$ \\
\hline \multirow{6}{*}{$\begin{array}{c}\text { White } \\
\text { Defendants }\end{array}$} & Mean Sentence Length (using 4 bins) & 41.4 & 41.4 & $49.0(15.7)$ & 0.642 \\
\hline & Mean Sentence Length (using 19 bins) & 41.4 & 41.4 & $46.2(19.1)$ & 0.806 \\
\hline & Median Sentence Length (using 19 bins) & 30.0 & 29.0 & $47.0(31.2)$ & 0.559 \\
\hline & 75th Quantile of Sentence Length (using 19 bins) & 70.0 & 70.4 & $52.1(34.0)$ & 0.586 \\
\hline & Prop. Conv of Life Sentence (using 4 bins) & 0.192 & 0.188 & $0.313(0.249)$ & 0.614 \\
\hline & Prop. Conv of Life Sentence (using 19 bins) & 0.192 & 0.153 & $0.229(0.264)$ & 0.773 \\
\hline \multirow{6}{*}{$\begin{array}{c}\text { Black } \\
\text { Defendants }\end{array}$} & Mean Sentence Length (using 4 bins) & 37.0 & 37.0 & $24.8(5.9)$ & 0.031 \\
\hline & Mean Sentence Length (using 19 bins) & 37.0 & 37.0 & $22.4(6.86)$ & 0.029 \\
\hline & Median Sentence Length (using 19 bins) & 27.5 & 31.5 & $16.0(8.21)$ & 0.055 \\
\hline & 75th Quantile of Sentence Length (using 19 bins) & 53.5 & 56.2 & $27.8(17.7)$ & 0.103 \\
\hline & Prop. Conv of Life Sentence (using 4 bins) & 0.131 & 0.119 & $0.042(0.024)$ & 0.001 \\
\hline & Prop. Conv of Life Sentence (using 19 bins) & 0.131 & 0.107 & $0.023(0.017)$ & 0.0000 \\
\hline
\end{tabular}

Note - Each row corresponds to a different simulation for white and black defendants, varying the number of bins to group zip codes (4 versus 19) and the outcome or parameter simulated. In the 19-bin simulations, the first 18 bins are intervals with a width of 0.1 beginning at a representation ratio of 0.2 ; the last bin includes all zip codes with a ratio greater than 2 . We use a logit model when estimating the proportion convicted of a life sentence, and a quantile regression when predicting the median and $75^{\text {th }}$ percentile. The table presents the actual value of the parameter of interest, and the simulated value when jury pools are reflective of the population, where standard errors of simulated value are in parentheses. 


\title{
Online Appendix Materials for:
}

Unequal Jury Representation and Its Consequences

\author{
Shamena Anwar \\ RAND Corporation \\ Patrick Bayer \\ Duke University \\ Randi Hjalmarsson \\ University of Gothenburg
}

This PDF file includes:

Appendix A. Data Appendix

Appendix B. Supplementary Tables ST1-ST8 


\section{Appendix A. Data Appendix}

\section{A1. Data Description and Sample Creation}

We received two data sets from the Harris County Clerk's Office: a defendant data set and a jury data set. The defendant data includes information on every felony case a jury made a decision on (verdict and/or sentencing) between May 31, 2005 and March 29, 2012. The defendant data included information on the name, date of birth, gender, zip code of residence, and criminal history of the defendant, as well as the case number, offense category and degree, verdict, sentence, date of filing and disposition. The defendant's race was provided, but their ethnicity was not; we used the defendant's name to code whether they were Hispanic or not. ${ }^{1}$ To find information on the start and end dates of the defendant's jury trial, and whether convicted defendants chose either a jury or a judge to sentence them, we used the defendant's name and case number to look up that information in the online Harris County Criminal Records system. ${ }^{2}$

We organized the data at the defendant-jury level, so that a defendant with multiple charges that went to the same jury was coded as one observation. We only kept cases where a jury verdict was listed, and then dropped the subset of these cases where the jury only did the sentencing (after the defendant had already pled guilty), leaving us with 2,365 cases. There are three types of case categories that remain: (1) cases where the jury made the decision to convict, but a judge did the sentencing; (2) cases where the jury made the decision to convict and did the sentencing; and (3) cases where the jury made the decision to acquit. For the cases in the last category, we do not observe who the defendant chose to do the sentencing if the jury had convicted them. However, we treat cases in this category as the jury sentencing the defendant to a sentence of zero years.

The juror demographic data set has the following information for each of the approximately 309,000 jurors that were empaneled for a jury trial between May 31, 2005 and March 14, 2012: case number, panel identification number, panel status (i.e., on the seated jury, struck, or dismissed), the juror's position in the panel, gender, birth date, and zip code of residence, as well as the date and time they were assigned to the panel, and the date and time they were released from the panel. ${ }^{3}$ Using the juror's zip code, we merge census data on the juror's neighborhood, including the racial composition, median income, population size, high school graduation rate, share with income below poverty, and share foreign born.

\section{Samples for Descriptive Analyses of Jury Pool and Defendant Representation in Section 2}

Section 2 of the paper presents a separate descriptive analysis of zip code representation in the jury pool and defendant populations and thus does not require a match of these two data sets. These analyses are thus based on the full datasets outlined above, with a few sample restrictions as described here related to the validity of the zip code variable in each dataset. Specifically,

\footnotetext{
${ }^{1}$ To determine whether a defendant was Hispanic, we first identified the list of the 600 most popular Hispanic surnames using census data. If a defendant's surname was on that list, we classified them as Hispanic. However, after doing this we found there were still many defendants that were coded as "white" that had distinctively Hispanic names. We thus went through the white defendants and manually coded them as Hispanic based on whether their name sounded Hispanic. For defendants that were subsequently incarcerated, one can manually look up these defendants in the Department of Corrections records where Hispanic status is coded. We did this for a random sample of the cases we manually coded (where the defendant was subsequently incarcerated) and found that our manual classifications were always correct. We also pulled out defendants that were classified as white but had distinctively Arab sounding names and coded them as "other".

${ }^{2}$ See http://www.hcdistrictclerk.com/Edocs/Public/search.aspx.

${ }^{3}$ Not all jury pools that were empaneled for a trial actually tried a case. Sometimes the case they were empaneled for was delayed and the entire panel was dismissed.
} 
we exclude jurors and defendants with missing zip code information, zip codes not matched to the 2000 Census, and zip codes outside Harris County. This yields an analysis sample of 299,945 jury pool members and 1,754 defendants from 129 zip codes from which we calculate jury and defendant representation ratios.

\section{Constructing the Sample to Examine the Effect of Jury Composition on Trial Outcomes Used in Sections 3 and 4}

Examining the impact of jury pool composition on trial outcomes required matching the defendant and jury pool data sets. Before conducting this match there were a few additional drops we made. ${ }^{4}$ With respect to the defendant data set, we dropped 65 cases where the defendant was not a white, Black, or Hispanic individual. We also dropped all of the 172 capital cases as there was no real outcome variation among these cases; only one defendant was not convicted. With these sample restrictions there are 2,128 cases remaining that can be potentially matched to the jury data. With respect to the jury data, we dropped jury panels for which we could not identify a seated jury. As noted to us by the court clerk, the panel status variable is not fully reliable, as sometimes everyone in the pool is incorrectly listed as struck. We thus used the jury panel's assignment and release dates to help determine who on the seated jury was seated or not, and dropped panels where this determination could not be made. ${ }^{5}$

A key issue that limited the ability to match the jury data with the defendant data is that the case number attached to a jury panel was sometimes wrong; this problem was noted to us by the court clerk when the data was provided. The court clerk also provided us with 62 defendantjury panel matches from the sample (the "test sample") that the office had manually matched and knew to be correct. This test sample allowed us to determine in what specific situations the case number attached to a jury panel would be incorrect, and to develop an algorithm that would allow the defendant data to be matched to the jury data. We detail the algorithm we developed in the next section. Our algorithm only allows us to match 1,316 of the 2,128 cases. However, we are very confident in the matches for those cases, as all cases in the test sample for which our algorithm could find a match were correct. As we show in Appendix Table ST1, the matched sample is relatively similar to the unmatched sample, except the matched sample has more female defendant and murder cases, as we more aggressively tried to match these cases.

This sample of 1,316 cases includes 329 cases where the jury makes the conviction decision and the judge makes the sentencing decision. Because in the majority of the cases the jury makes both decisions, and we want to look at both the conviction and sentencing stage simultaneously for our main outcome, we drop the 329 cases where the judge conducts the

\footnotetext{
${ }^{4}$ Note that the defendant and jury data sets we start with here are not the same as those used in Section 3, because we do not make the same zip code drops as were done there. Specifically, the only drop made based on zip code is that any panel where the jurors zip codes were missing were dropped-this was done at the end of the matching process and resulted in six cases being dropped.

${ }^{5}$ Any panel for which the panel status identified between 12-15 members as being on the seated jury was treated as correct, as this is the expected number of seated jurors for a trial (including alternates). For cases that did not fall into this category, we used the jury panel's assignment and release dates to help identify the seated jurors. Specifically, jurors that are seated should be released at a time that will be equal to the time at which the last juror in that panel is released. If the number of potential jurors that are released at the latest time is between 12-15, we identify these jurors as the seated jurors. We could not identify a seated jury in cases that did not fall into either of the above two categories. This could either be because there was no seated jury, or because the data does not allow us to identify it. Note that we are only identifying jurors that are seated versus not. For jurors that are not seated, we do not seek to distinguish between whether they were struck for cause, dismissed via peremptory challenge, or not reached.
} 
sentencing and consider only those remaining cases where the jury makes both decisions. Finally, we omit 6 cases where the main variables of interests - i.e. zip code characteristics and representation ratios - cannot be created because the juror zip codes were missing for these cases.

Of these 981 cases that remain, about $75 \%$ are life-sentence eligible, either because of the severity of the current offenses or a combination of the current offense and criminal history. As noted in Section 1, all results presented in Sections 3 and 4 are run on the sample of 734 trials where a life sentence is a possible outcome.

\section{A2. Matching Jury Pool and Defendant Trial Data Sets}

This section details the reasons why it was difficult to match the defendant data to the jury data, and describes the matching algorithm we developed. The Harris County Clerk's office provided information regarding why some of the cases were difficult to match; they also manually matched 62 defendant cases to the correct jury panel and provided this to us. This test sample is what allowed us to better understand the specific reasons the cases were difficult to match, and allowed us to develop an algorithm whose accuracy could be checked. While the eventual algorithm we developed only allowed us to match $62 \%$ of our defendant sample, the accuracy of this matching method for the test sample was $100 \%$.

The key difficulty in developing a crosswalk for the jury and defendant datasets was that the case number that was attached to a jury panel was sometimes incorrect. As noted by the court clerk, a jury panel would be pulled for a case that was supposed to go to trial that day. The jury panel would then be assigned the case number for that trial. However, sometimes that jury trial got delayed, or a plea deal was struck, and the jury panel ended up being assigned to a different case that went to trial that day. Unfortunately, the old case number remained linked to the jury panel. Thus matching cases and jury panels up on case number alone is not a sufficient matching method.

A second related issue is that because jury trials get delayed, there are sometimes multiple panels that are assigned to a given case number. The first few panels that were called for case A could have then been seated for another case, or dismissed completely. Again, one cannot just do a straight case number match between the data sets, as it would result in many different panels being assigned to a case, when only one actually saw the case.

A third issue is that sometimes a defendant is on trial for multiple charges, where each charge has a different case number. The jury panel is only attached to one of those case numbers, even though they issued verdicts on all of the charges. However, sometimes a defendant will have some of the charges dismissed right before the jury trial, but the jury panel will still be attached to one of these dismissed charges. As this dismissed charge is not one where a jury rendered a verdict, there is no case number match in the defendant data set.

Below we discuss the specific matching algorithm we used:

1) Only jury panels that had an identifiable seated jury were eligible to be matched. Note that if a jury panel assigned to case A did not have any seated jurors, it implies that while it was originally assigned to case A, it was dismissed because case A ended up not going to trial that day. However, as we discussed above, it was sometimes difficult to tell if a jury had seated jurors. There is thus a possibility we are dropping some juries that in fact did have a seated jury, which eliminates some potential matches. 
2) If there was a case number match between a defendant and a jury panel, and the disposition date in the defendant data was within 6 days of the last release date for the matched jury panel, this was classified as a match. Note that if the jury trial was pulled for case A on day X, and case A went to trial on day X, the match should be correct. This is because cases only get incorrectly matched when the original trial is delayed and the new panel seated for case A is also misclassified; however, if this were to happen, the dates for case A's trial would not match the jury panel start and release date. Because there is likely to be some margin of error on the date variables, we allowed the dates to be within 6 days of each other. ${ }^{6,7}$ Note that often there were multiple panels associated with one case number. If we could not identify a unique panel whose release date was within six days of the disposition date, we did not classify it as a match.

3) If a jury panel had a case number that corresponded to a dismissed charge for defendant $A$, we classified that panel as having tried the other charges for defendant $A$ that did go to trial. This matching process was conducted by first pulling a defendant's name that had not been matched by the previous process. We looked the defendant's name up in Harris County's online criminal records system and found all charges (which will have unique case numbers) that would have gone to trial at around the same time. We often found that some of the charges had been dismissed right before the case for the other charges went to trial. For each of these dismissed charges, we tried to match the associated case number to a jury panel. If we found a jury panel that had a matching case number, and the trial disposition and juror release dates were within 6 days, this was classified as a match. This was an extremely tedious matching process, and thus we only attempted to do this with defendant groups we wanted to increase the sample size for. These groups included cases with murder charges (as these were the most serious charges in our sample), and cases with female defendants (as we thought we might be able to conduct comparisons of female and male defendants).

To analyze how our match process performed we used the test sample provided by the county clerk which provided the correct defendant-jury panel matches for 62 defendant cases. Using our above described matching procedure, we could identify matches for 57 of the 62 cases. Comparing our identified matches with the correct matches the clerk provided indicated that our algorithm got all of these matches correct. Thus, the upside to our match algorithm is that all of the matches it makes seem to be correct. The downside is that there will be cases (five in the test sample) for which we cannot find a match. For the five test cases we couldn't match, we used the jury panel that was identified to be correct in the test sample.

Applying our matching algorithm to the full sample of 2,128 cases allowed us to match 1,316 cases. Note that a likely reason the fraction of cases we were able to match in the full sample was smaller than in the test sample is because we only used step 3 in our algorithm described above on a select sample of cases, although we performed this step for all cases in the test sample. Because we are unable to match a reasonable fraction of the defendant sample, it is important to examine how the unmatched sample compares to the matched sample. Table ST1 compares the defendant and case characteristics between the matched and the unmatched sample. The results reveal that the matched sample has more females and more murder cases.

\footnotetext{
${ }^{6} 93.4 \%$ of the resulting matched sample has a defendant disposition date that is within one day of the jury's last release date.

${ }^{7}$ If the original trial is cancelled (e.g. the defendant takes a plea deal), there is no possibility of a match, as the case number the jury was pulled for will correspond to a defendant that did not have a jury trial and is thus not in the defendant data set.
} 
This is to be expected as we only tried step 3 in our algorithm on these cases, and thus they compose a higher fraction of the matched sample. The fact that the matched sample has roughly double the murder cases than the unmatched sample is likely the reason that we find the matched sample has a larger proportion of life-sentence eligible cases and first and second degree felonies, and that the average incarceration length is longer. This implies that if we had not tried to overmatch female defendant and murder cases, the ability to match a defendant to their jury panel would have been relatively random. 
Appendix B. Supplementary Tables

ST1: A Comparison of the Defendant Sample That Can be Matched to a Jury with the Defendant Sample That Cannot be Matched to a Jury

\begin{tabular}{|c|c|c|c|}
\hline & $\begin{array}{c}\text { Matched } \\
\text { Sample }\end{array}$ & $\begin{array}{c}\text { Unmatched } \\
\text { Sample }\end{array}$ & $\begin{array}{l}\mathrm{p} \text {-value for } \\
\text { difference }\end{array}$ \\
\hline \multicolumn{4}{|l|}{ Defendant Characteristics } \\
\hline Black Defendant & 0.575 & 0.578 & 0.915 \\
\hline Hispanic Defendant & 0.262 & 0.281 & 0.347 \\
\hline White Defendant & 0.163 & 0.142 & 0.194 \\
\hline Female Defendant & 0.082 & 0.043 & 0.001 \\
\hline Average Age of Defendant & 34.6 & 34.4 & 0.617 \\
\hline \multicolumn{4}{|l|}{ Case Characteristics } \\
\hline Total Charges & 1.15 & 1.16 & 0.769 \\
\hline Life Sentence Eligible & 0.714 & 0.670 & 0.034 \\
\hline 1st Degree Felony & 0.553 & 0.509 & 0.045 \\
\hline 2nd Degree Felony & 0.239 & 0.207 & 0.083 \\
\hline 3rd Degree Felony & 0.102 & 0.127 & 0.075 \\
\hline State Jail Felony & 0.084 & 0.119 & 0.007 \\
\hline Any Drug Charge & 0.132 & 0.183 & 0.001 \\
\hline Any Murder Charge & 0.198 & 0.097 & 0.000 \\
\hline Any Robbery Charge & 0.176 & 0.197 & 0.231 \\
\hline Any Other Violent Charge & 0.116 & 0.123 & 0.634 \\
\hline Any Property Charge & 0.110 & 0.121 & 0.459 \\
\hline Any Sex Charge & 0.184 & 0.175 & 0.600 \\
\hline Any Weapons Charge & 0.020 & 0.030 & 0.147 \\
\hline \multicolumn{4}{|l|}{ Criminal History } \\
\hline Any Past 1 st Degree Felonies & 0.114 & 0.105 & 0.506 \\
\hline Any Past 2nd Degree Felonies & 0.223 & 0.240 & 0.373 \\
\hline Any Past 3rd Degree Felonies & 0.200 & 0.193 & 0.715 \\
\hline Any Past State Jail Felonies & 0.141 & 0.169 & 0.087 \\
\hline Any Past Misdemeanors & 0.530 & 0.505 & 0.268 \\
\hline Any Past Times in Prison & 0.318 & 0.314 & 0.834 \\
\hline Any Past Times in Jail & 0.510 & 0.493 & 0.439 \\
\hline \multicolumn{4}{|l|}{ Sentence Variables } \\
\hline Judge does Sentencing & 0.250 & 0.282 & 0.103 \\
\hline Any Conviction & 0.913 & 0.898 & 0.253 \\
\hline Incarceration Length (years w/acquittal=0) & 29.8 & 25.3 & 0.001 \\
\hline Observations & 1316 & 812 & \\
\hline
\end{tabular}




\begin{tabular}{|c|c|c|c|c|}
\hline & All Cases & $\begin{array}{c}\text { White } \\
\text { Defendants }\end{array}$ & $\begin{array}{c}\text { Black } \\
\text { Defendants }\end{array}$ & $\begin{array}{c}\text { Hispanic } \\
\text { Defendants }\end{array}$ \\
\hline \multicolumn{5}{|l|}{ Defendant Characteristics } \\
\hline White Defendant & 0.142 & & & \\
\hline Black Defendant & 0.594 & & & \\
\hline Hispanic Defendant & 0.264 & & & \\
\hline Female Defendant & 0.060 & 0.115 & 0.057 & 0.036 \\
\hline Average Age at Filing & 33.2 & 37.9 & 32.4 & 32.4 \\
\hline \multicolumn{5}{|l|}{ Case Characteristics } \\
\hline More Than One Charge & 0.124 & 0.135 & 0.110 & 0.149 \\
\hline 1st Degree Felony & 0.812 & 0.808 & 0.775 & 0.897 \\
\hline 2nd Degree Felony & 0.144 & 0.135 & 0.177 & 0.077 \\
\hline 3rd Degree Felony & 0.044 & 0.058 & 0.048 & 0.026 \\
\hline Any Drug Charge & 0.097 & 0.029 & 0.117 & 0.088 \\
\hline Any Murder Charge & 0.283 & 0.317 & 0.271 & 0.294 \\
\hline Any Robbery Charge & 0.240 & 0.144 & 0.280 & 0.201 \\
\hline Any Other Violent Charge & 0.086 & 0.058 & 0.112 & 0.041 \\
\hline Any Property Charge & 0.076 & 0.096 & 0.078 & 0.062 \\
\hline Any Sex Charge & 0.188 & 0.279 & 0.128 & 0.273 \\
\hline Any Weapons Charge & 0.018 & 0 & 0.028 & 0.005 \\
\hline \multicolumn{5}{|l|}{ Criminal History } \\
\hline Any Past 1st Degree Felonies & 0.127 & 0.067 & 0.158 & 0.088 \\
\hline Any Past 2nd Degree Felonies & 0.252 & 0.212 & 0.294 & 0.180 \\
\hline Any Past 3rd Degree Felonies & 0.211 & 0.202 & 0.250 & 0.129 \\
\hline Any Past Times in Prison & 0.339 & 0.279 & 0.397 & 0.242 \\
\hline Any Past Times in Jail & 0.515 & 0.442 & 0.569 & 0.433 \\
\hline \multicolumn{5}{|l|}{ Outcome Variables } \\
\hline Any Conviction & 0.903 & 0.942 & 0.894 & 0.902 \\
\hline Convicted of a Life Sentence & 0.147 & 0.192 & 0.131 & 0.160 \\
\hline $\begin{array}{r}\text { Incarceration Length (years } \\
\text { w/acquittals }=0 \text { ) }\end{array}$ & 38.8 & 42.0 & 37.2 & 40.5 \\
\hline Observations & 734 & 104 & 436 & 194 \\
\hline
\end{tabular}

Note - This table presents summary statistics for the sample of defendants (overall and by race/ethnicity) eligible for a life sentence. The sample is restricted to those cases for which the jury and defendant data sets could be matched. 
ST3: The Relationship Between Case Characteristics and Zip Code Representation in Jury Pools

\begin{tabular}{|c|c|c|c|c|}
\hline & \multicolumn{4}{|c|}{ Proportion of Jury Pool in Each Quartile of Representation Ratio: } \\
\hline & Quartile 1 & Quartile 2 & Quartile 3 & Quartile 4 \\
\hline Male Defendant & $\begin{array}{l}-0.00341 \\
(0.00936)\end{array}$ & $\begin{array}{l}-0.00642 \\
(0.00865)\end{array}$ & $\begin{array}{c}0.00329 \\
(0.00866)\end{array}$ & $\begin{array}{c}0.00654 \\
(0.00949)\end{array}$ \\
\hline Black Defendant & $\begin{array}{c}0.00807 \\
(0.00654)\end{array}$ & $\begin{array}{l}-0.00164 \\
(0.00605)\end{array}$ & $\begin{array}{l}-0.0105 * \\
(0.00606)\end{array}$ & $\begin{array}{c}0.00403 \\
(0.00664)\end{array}$ \\
\hline Hispanic Defendant & $\begin{array}{c}0.0111 \\
(0.00712)\end{array}$ & $\begin{array}{l}-0.00737 \\
(0.00658)\end{array}$ & $\begin{array}{l}-0.0117 * \\
(0.00659)\end{array}$ & $\begin{array}{c}0.00796 \\
(0.00722)\end{array}$ \\
\hline Age at Filing & $\begin{array}{c}0.000243 \\
(0.000212)\end{array}$ & $\begin{array}{c}-0.000342 * \\
(0.000196)\end{array}$ & $\begin{array}{c}0.000191 \\
(0.000196)\end{array}$ & $\begin{array}{c}-0.0000919 \\
(0.000215)\end{array}$ \\
\hline Number of Charges & $\begin{array}{c}-0.00407 \\
(0.00460)\end{array}$ & $\begin{array}{l}0.000619 \\
(0.00426)\end{array}$ & $\begin{array}{l}-0.00225 \\
(0.00426)\end{array}$ & $\begin{array}{c}0.00570 \\
(0.00467)\end{array}$ \\
\hline Any Drug Charge & $\begin{array}{l}0.0194 * \\
(0.0113)\end{array}$ & $\begin{array}{r}-0.00883 \\
(0.0105)\end{array}$ & $\begin{array}{c}-0.000697 \\
(0.0105)\end{array}$ & $\begin{array}{c}-0.00989 \\
(0.0115)\end{array}$ \\
\hline Any Murder Charge & $\begin{array}{l}0.00944 \\
(0.0101)\end{array}$ & $\begin{array}{c}-0.0100 \\
(0.00935)\end{array}$ & $\begin{array}{l}-0.00639 \\
(0.00936)\end{array}$ & $\begin{array}{l}0.00696 \\
(0.0103)\end{array}$ \\
\hline Any Robbery Charge & $\begin{array}{c}0.00658 \\
(0.0101)\end{array}$ & $\begin{array}{l}-0.00605 \\
(0.00939)\end{array}$ & $\begin{array}{l}-0.00636 \\
(0.00939)\end{array}$ & $\begin{array}{l}0.00583 \\
(0.0103)\end{array}$ \\
\hline Any Other Violent Charge & $\begin{array}{c}0.0225^{* *} \\
(0.0107)\end{array}$ & $\begin{array}{c}-0.0155 \\
(0.00990)\end{array}$ & $\begin{array}{r}-0.000796 \\
(0.00991)\end{array}$ & $\begin{array}{r}-0.00617 \\
(0.0109)\end{array}$ \\
\hline Any Property Charge & $\begin{array}{c}-0.000196 \\
(0.0111)\end{array}$ & $\begin{array}{c}0.000801 \\
(0.0103)\end{array}$ & $\begin{array}{l}-0.0115 \\
(0.0103)\end{array}$ & $\begin{array}{c}0.0109 \\
(0.0113)\end{array}$ \\
\hline Any Sex Charge & $\begin{array}{c}0.000641 \\
(0.0109)\end{array}$ & $\begin{array}{r}-0.00481 \\
(0.0101)\end{array}$ & $\begin{array}{r}-0.00389 \\
(0.0101)\end{array}$ & $\begin{array}{l}0.00806 \\
(0.0111)\end{array}$ \\
\hline Any Weapons Charge & $\begin{array}{c}0.0123 \\
(0.0172)\end{array}$ & $\begin{array}{c}-0.0169 \\
(0.0159)\end{array}$ & $\begin{array}{l}0.00769 \\
(0.0159)\end{array}$ & $\begin{array}{r}-0.00312 \\
(0.0175)\end{array}$ \\
\hline 1st Degree Felony & $\begin{array}{c}0.00115 \\
(0.00727)\end{array}$ & $\begin{array}{c}-0.00161 \\
(0.00673)\end{array}$ & $\begin{array}{l}-0.00249 \\
(0.00673)\end{array}$ & $\begin{array}{c}0.00295 \\
(0.00738)\end{array}$ \\
\hline Any Prior Felonies & $\begin{array}{c}0.00333 \\
(0.00524)\end{array}$ & $\begin{array}{c}0.00171 \\
(0.00485)\end{array}$ & $\begin{array}{l}-0.00604 \\
(0.00485)\end{array}$ & $\begin{array}{l}0.000988 \\
(0.00532)\end{array}$ \\
\hline Constant & $\begin{array}{c}0.233 * * * \\
(0.0156)\end{array}$ & $\begin{array}{c}0.273 * * * \\
(0.0144)\end{array}$ & $\begin{array}{c}0.258 * * * \\
(0.0144)\end{array}$ & $\begin{array}{c}0.236 * * * \\
(0.0158)\end{array}$ \\
\hline Observations & 734 & 734 & 734 & 734 \\
\hline $\begin{array}{l}\mathrm{p} \text {-value for whether all } \\
\text { coeff jointly equal zero }\end{array}$ & 0.1855 & 0.7084 & 0.7699 & 0.5234 \\
\hline R-squared & 0.025 & 0.015 & 0.014 & 0.018 \\
\hline
\end{tabular}

Note: All regressions use OLS and standard errors are in parentheses. ***, and *** indicate the coefficient is significant at the $10 \%, 5 \%$, and $1 \%$ level, respectively. 
ST4: The Relationship Between Case Characteristics and Jury Pool Characteristics

\begin{tabular}{|c|c|c|c|c|c|c|c|c|}
\hline & $\begin{array}{l}\text { Avg. \% } \\
\text { White in } \\
\text { Jury } \\
\text { Pool's } \\
\text { Zip } \\
\text { Codes } \\
\text { (1) }\end{array}$ & $\begin{array}{l}\text { Avg. \% } \\
\text { Black in } \\
\text { Jury } \\
\text { Pool's } \\
\text { Zip } \\
\text { Codes } \\
\text { (2) }\end{array}$ & $\begin{array}{l}\text { Avg. \% } \\
\text { Hispanic } \\
\text { in Jury } \\
\text { Pool's } \\
\text { Zip } \\
\text { Codes } \\
\text { (3) }\end{array}$ & $\begin{array}{l}\text { Avg. Age } \\
\text { of Jury } \\
\text { Pool } \\
(4)\end{array}$ & $\begin{array}{c}\text { Proportion } \\
\text { of Males } \\
\text { in Jury } \\
\text { Pool } \\
\text { (5) }\end{array}$ & $\begin{array}{c}\text { Avg. } \\
\text { Median } \\
\text { Family } \\
\text { Income in } \\
\text { Jury Pool's } \\
\text { Zip Codes } \\
\text { (6) }\end{array}$ & $\begin{array}{l}\text { Avg. High } \\
\text { School } \\
\text { Graduation } \\
\text { Rate in } \\
\text { Jury Pool's } \\
\text { Zip Codes } \\
\text { (7) }\end{array}$ & $\begin{array}{l}\text { Avg \% of } \\
\text { Foreign } \\
\text { Born } \\
\text { Individuals } \\
\text { in Jury } \\
\text { Pool's Zip } \\
\text { Codes } \\
\text { (8) }\end{array}$ \\
\hline Male Defendant & $\begin{array}{c}0.124 \\
(0.564)\end{array}$ & $\begin{array}{c}0.291 \\
(0.401)\end{array}$ & $\begin{array}{l}-0.517 \\
(0.385)\end{array}$ & $\begin{array}{c}0.152 \\
(0.272)\end{array}$ & $\begin{array}{l}-0.00764 \\
(0.0103)\end{array}$ & $\begin{array}{c}502.2 \\
(551.2)\end{array}$ & $\begin{array}{c}0.320 \\
(0.326)\end{array}$ & $\begin{array}{l}-0.157 \\
(0.208)\end{array}$ \\
\hline Black Defendant & $\begin{array}{l}-0.400 \\
(0.395)\end{array}$ & $\begin{array}{c}0.274 \\
(0.281)\end{array}$ & $\begin{array}{c}0.222 \\
(0.269)\end{array}$ & $\begin{array}{l}-0.203 \\
(0.191)\end{array}$ & $\begin{array}{c}0.00227 \\
(0.00720)\end{array}$ & $\begin{array}{l}-481.4 \\
(385.6)\end{array}$ & $\begin{array}{l}-0.182 \\
(0.228)\end{array}$ & $\begin{array}{l}-0.0666 \\
(0.145)\end{array}$ \\
\hline Hispanic Defendant & $\begin{array}{l}-0.113 \\
(0.429)\end{array}$ & $\begin{array}{c}0.176 \\
(0.305)\end{array}$ & $\begin{array}{l}-0.0336 \\
(0.293)\end{array}$ & $\begin{array}{l}-0.0573 \\
(0.207)\end{array}$ & $\begin{array}{c}0.00297 \\
(0.00783)\end{array}$ & $\begin{array}{l}-235.7 \\
(419.4)\end{array}$ & $\begin{array}{c}0.00300 \\
(0.248)\end{array}$ & $\begin{array}{l}-0.0981 \\
(0.158)\end{array}$ \\
\hline Age at Filing & $\begin{array}{l}-0.0101 \\
(0.0128)\end{array}$ & $\begin{array}{c}0.0125 \\
(0.00907)\end{array}$ & $\begin{array}{l}0.000633 \\
(0.00871)\end{array}$ & $\begin{array}{c}0.00452 \\
(0.00616)\end{array}$ & $\begin{array}{c}0.000388^{*} \\
(0.000233)\end{array}$ & $\begin{array}{l}-6.353 \\
(12.47)\end{array}$ & $\begin{array}{l}-0.00712 \\
(0.00736)\end{array}$ & $\begin{array}{l}-0.00364 \\
(0.00470)\end{array}$ \\
\hline Number of Charges & $\begin{array}{c}-0.00208 \\
(0.278)\end{array}$ & $\begin{array}{l}-0.214 \\
(0.197)\end{array}$ & $\begin{array}{c}0.166 \\
(0.189)\end{array}$ & $\begin{array}{c}0.121 \\
(0.134)\end{array}$ & $\begin{array}{l}-0.000774 \\
(0.00506)\end{array}$ & $\begin{array}{l}-8.851 \\
(271.1)\end{array}$ & $\begin{array}{l}0.0141 \\
(0.160)\end{array}$ & $\begin{array}{l}0.0673 \\
(0.102)\end{array}$ \\
\hline Any Drug Charge & $\begin{array}{l}-0.911 \\
(0.683)\end{array}$ & $\begin{array}{c}0.248 \\
(0.485)\end{array}$ & $\begin{array}{c}0.630 \\
(0.466)\end{array}$ & $\begin{array}{c}0.513 \\
(0.330)\end{array}$ & $\begin{array}{c}0.0145 \\
(0.0125)\end{array}$ & $\begin{array}{l}-687.6 \\
(667.0)\end{array}$ & $\begin{array}{l}-0.663 * \\
(0.394)\end{array}$ & $\begin{array}{l}0.451 * \\
(0.251)\end{array}$ \\
\hline Any Murder Charge & $\begin{array}{l}-0.841 \\
(0.610)\end{array}$ & $\begin{array}{c}0.438 \\
(0.433)\end{array}$ & $\begin{array}{c}0.465 \\
(0.416)\end{array}$ & $\begin{array}{c}0.274 \\
(0.294)\end{array}$ & $\begin{array}{c}0.0167 \\
(0.0111)\end{array}$ & $\begin{array}{l}-431.1 \\
(595.6)\end{array}$ & $\begin{array}{l}-0.600 * \\
(0.352)\end{array}$ & $\begin{array}{c}0.205 \\
(0.224)\end{array}$ \\
\hline Any Robbery Charge & $\begin{array}{l}-0.493 \\
(0.612)\end{array}$ & $\begin{array}{c}0.203 \\
(0.435)\end{array}$ & $\begin{array}{c}0.271 \\
(0.417)\end{array}$ & $\begin{array}{c}0.462 \\
(0.295)\end{array}$ & $\begin{array}{l}0.0215^{*} \\
(0.0112)\end{array}$ & $\begin{array}{c}32.75 \\
(597.8)\end{array}$ & $\begin{array}{l}-0.340 \\
(0.353)\end{array}$ & $\begin{array}{c}0.206 \\
(0.225)\end{array}$ \\
\hline Any Other Violent Charge & $\begin{array}{c}-1.336^{* *} \\
(0.646)\end{array}$ & $\begin{array}{c}0.519 \\
(0.459)\end{array}$ & $\begin{array}{l}0.837 * \\
(0.440)\end{array}$ & $\begin{array}{c}0.322 \\
(0.312)\end{array}$ & $\begin{array}{c}0.0128 \\
(0.0118)\end{array}$ & $\begin{array}{l}-493.8 \\
(630.7)\end{array}$ & $\begin{array}{c}-0.892 * * \\
(0.372)\end{array}$ & $\begin{array}{c}0.503 * * \\
(0.237)\end{array}$ \\
\hline Any Property Charge & $\begin{array}{l}-0.352 \\
(0.670)\end{array}$ & $\begin{array}{c}0.193 \\
(0.476)\end{array}$ & $\begin{array}{c}0.164 \\
(0.457)\end{array}$ & $\begin{array}{c}0.106 \\
(0.324)\end{array}$ & $\begin{array}{c}0.0242 * * \\
(0.0122)\end{array}$ & $\begin{array}{c}310.2 \\
(654.9)\end{array}$ & $\begin{array}{l}-0.263 \\
(0.387)\end{array}$ & $\begin{array}{l}0.0279 \\
(0.247)\end{array}$ \\
\hline Any Sex Charge & $\begin{array}{l}-0.361 \\
(0.659)\end{array}$ & $\begin{array}{c}0.300 \\
(0.469)\end{array}$ & $\begin{array}{l}0.0385 \\
(0.450)\end{array}$ & $\begin{array}{c}0.154 \\
(0.318)\end{array}$ & $\begin{array}{l}0.00783 \\
(0.0120)\end{array}$ & $\begin{array}{c}179.8 \\
(644.0)\end{array}$ & $\begin{array}{l}-0.156 \\
(0.380)\end{array}$ & $\begin{array}{c}0.154 \\
(0.243)\end{array}$ \\
\hline Any Weapons Charge & $\begin{array}{c}0.574 \\
(1.039)\end{array}$ & $\begin{array}{l}-0.584 \\
(0.738)\end{array}$ & $\begin{array}{l}-0.123 \\
(0.708)\end{array}$ & $\begin{array}{c}0.362 \\
(0.501)\end{array}$ & $\begin{array}{l}0.00743 \\
(0.0190)\end{array}$ & $\begin{array}{c}1483.1 \\
(1014.8)\end{array}$ & $\begin{array}{c}0.189 \\
(0.599)\end{array}$ & $\begin{array}{c}0.355 \\
(0.382)\end{array}$ \\
\hline 1st Degree Felony & $\begin{array}{l}0.0931 \\
(0.439)\end{array}$ & $\begin{array}{c}0.130 \\
(0.312)\end{array}$ & $\begin{array}{l}-0.131 \\
(0.299)\end{array}$ & $\begin{array}{l}-0.0221 \\
(0.212)\end{array}$ & $\begin{array}{l}-0.00874 \\
(0.00800)\end{array}$ & $\begin{array}{c}28.42 \\
(428.4)\end{array}$ & $\begin{array}{l}0.0275 \\
(0.253)\end{array}$ & $\begin{array}{l}-0.152 \\
(0.161)\end{array}$ \\
\hline Any Prior Felonies & $\begin{array}{l}0.0587 \\
(0.316)\end{array}$ & $\begin{array}{r}-0.0432 \\
(0.225)\end{array}$ & $\begin{array}{c}-0.00396 \\
(0.216)\end{array}$ & $\begin{array}{l}-0.0258 \\
(0.153)\end{array}$ & $\begin{array}{l}-0.00443 \\
(0.00577)\end{array}$ & $\begin{array}{l}-101.9 \\
(308.8)\end{array}$ & $\begin{array}{l}-0.0214 \\
(0.182)\end{array}$ & $\begin{array}{l}-0.0324 \\
(0.116)\end{array}$ \\
\hline Constant & $\begin{array}{c}54.59 * * * \\
(0.939)\end{array}$ & $\begin{array}{c}13.48 * * * \\
(0.667)\end{array}$ & $\begin{array}{c}25.16 * * * \\
(0.640) \\
\end{array}$ & $\begin{array}{c}46.92^{* * * *} \\
(0.453)\end{array}$ & $\begin{array}{l}0.469 * * * \\
(0.0171)\end{array}$ & $\begin{array}{c}63072.3^{* * * *} \\
(916.9)\end{array}$ & $\begin{array}{c}81.34 * * * \\
(0.542)\end{array}$ & $\begin{array}{c}17.95 * * * \\
(0.345)\end{array}$ \\
\hline $\begin{array}{l}\text { Observations } \\
\text { p-value: all coef jointly }=0\end{array}$ & $\begin{array}{c}734 \\
0.6753\end{array}$ & $\begin{array}{c}734 \\
0.8679\end{array}$ & $\begin{array}{c}734 \\
0.3523\end{array}$ & $\begin{array}{c}734 \\
0.8163\end{array}$ & $\begin{array}{c}734 \\
0.671\end{array}$ & $\begin{array}{c}734 \\
0.5285\end{array}$ & $\begin{array}{c}734 \\
0.2484\end{array}$ & $\begin{array}{c}734 \\
0.4542\end{array}$ \\
\hline $\mathrm{R}$-squared & 0.015 & 0.012 & 0.021 & 0.013 & 0.015 & 0.018 & 0.023 & 0.019 \\
\hline
\end{tabular}


ST5: Relationship Between Jury Pool Representation and Trial Outcomes for Hispanic Defendants

\begin{tabular}{|c|c|c|c|}
\hline & \multicolumn{2}{|c|}{$\begin{array}{l}\text { Sentence Length (years } \\
\text { w/acquittals }=0 \text { ) }\end{array}$} & \multirow{2}{*}{$\begin{array}{l}\text { Convicted of a } \\
\text { Life Sentence } \\
(3)\end{array}$} \\
\hline & $(1)$ & $(2)$ & \\
\hline Proportion of Pool in $Q 1$ & $\begin{array}{c}12.93 \\
(38.56)\end{array}$ & $\begin{array}{c}1.836 \\
(44.23)\end{array}$ & $\begin{array}{l}0.0876 \\
(0.494)\end{array}$ \\
\hline Proportion of Pool in $Q 4$ & $\begin{array}{c}27.66 \\
(38.01)\end{array}$ & $\begin{array}{l}-15.38 \\
(43.88)\end{array}$ & $\begin{array}{l}-0.566 \\
(0.490)\end{array}$ \\
\hline Constant & $\begin{array}{c}19.85 \\
(17.06)\end{array}$ & $\begin{array}{c}43.40^{* *} \\
(19.58) \\
\end{array}$ & $\begin{array}{c}0.286 \\
(0.219)\end{array}$ \\
\hline Full Sample or Life Sent. Elig. (LSE)? & Full & LSE & LSE \\
\hline Defendant Race & Hispanic & Hispanic & Hispanic \\
\hline Observations & 264 & 194 & 194 \\
\hline R-Squared & 0.002 & 0.001 & 0.010 \\
\hline
\end{tabular}


ST6: Robustness of Relationship Between Jury Pool Representation and Trial Outcomes for Black Defendants

\begin{tabular}{|c|c|c|c|c|c|c|c|}
\hline & $\begin{array}{l}\text { Sentence } \\
\text { Length } \\
\text { (1) }\end{array}$ & $\begin{array}{l}\text { Log of } \\
\text { Sentence } \\
\text { Length } \\
\text { (2) }\end{array}$ & $\begin{array}{c}\text { Sentence } \\
\text { Length } \\
\text { Topcoded at } \\
\text { Age } 90 \\
\text { (3) }\end{array}$ & $\begin{array}{c}\text { Years Until } \\
\text { Parole } \\
\text { Eligible } \\
\text { (4) }\end{array}$ & $\begin{array}{l}\text { Median } \\
\text { Sentence } \\
\text { Length } \\
\text { (5) }\end{array}$ & $\begin{array}{c}\text { 70th } \\
\text { percentile of } \\
\text { Sentence } \\
\text { Length } \\
\text { Distribution } \\
\text { (6) }\end{array}$ & $\begin{array}{c}\text { 80th } \\
\text { percentile } \\
\text { of Sentence } \\
\text { Length } \\
\text { Distribution } \\
\text { (7) }\end{array}$ \\
\hline Proportion of Pool in Q1 & $\begin{array}{c}3.229 \\
(29.13)\end{array}$ & $\begin{array}{c}-0.375 \\
(1.283)\end{array}$ & $\begin{array}{l}-2.129 \\
(18.79)\end{array}$ & $\begin{array}{c}0.414 \\
(9.483)\end{array}$ & $\begin{array}{c}35.54 \\
(32.78)\end{array}$ & $\begin{array}{l}-1.620 \\
(66.00)\end{array}$ & $\begin{array}{l}-50.17 \\
(91.56)\end{array}$ \\
\hline Proportion of Pool in Q4 & $\begin{array}{c}92.06 * * * \\
(29.36)\end{array}$ & $\begin{array}{c}3.369 * * * \\
(1.293)\end{array}$ & $\begin{array}{c}52.13^{* * *} \\
(18.94)\end{array}$ & $\begin{array}{c}26.70 * * * \\
(9.558)\end{array}$ & $\begin{array}{c}132.7 * * * \\
(33.04)\end{array}$ & $\begin{array}{l}113.6^{*} \\
(66.52)\end{array}$ & $\begin{array}{l}170.9^{*} \\
(92.29)\end{array}$ \\
\hline Constant & $\begin{array}{c}12.64 \\
(12.63) \\
\end{array}$ & $\begin{array}{c}2.272 * * * \\
(0.556) \\
\end{array}$ & $\begin{array}{c}16.49^{* *} \\
(8.148) \\
\end{array}$ & $\begin{array}{c}6.126 \\
(4.112) \\
\end{array}$ & $\begin{array}{l}-12.29 \\
(14.22) \\
\end{array}$ & $\begin{array}{c}15.50 \\
(28.62) \\
\end{array}$ & $\begin{array}{c}37.07 \\
(39.71) \\
\end{array}$ \\
\hline Regression Method & OLS & OLS & OLS & OLS & quantile & quantile & quantile \\
\hline Observations & 436 & 436 & 436 & 436 & 436 & 436 & 436 \\
\hline
\end{tabular}


ST7: Which Jury Pool Characteristics Impact the Likelihood of Being Convicted of a Life Sentence?

\begin{tabular}{|c|c|c|c|c|c|c|}
\hline & \multicolumn{6}{|c|}{ Dependent Variable $=$ Convicted of a Life Sentence } \\
\hline & \multicolumn{3}{|c|}{ White Defendants } & \multicolumn{3}{|c|}{$\underline{\text { Black Defendants }}$} \\
\hline & (1) & (2) & (3) & (4) & $(5)$ & $(6)$ \\
\hline \multirow[t]{2}{*}{ Proportion of Jury Pool from Zip Codes > $76 \%$ White } & -0.323 & -0.314 & -0.425 & $0.584^{*}$ & 0.346 & 0.305 \\
\hline & $(0.877)$ & $(1.075)$ & $(1.059)$ & $(0.347)$ & $(0.406)$ & $(0.414)$ \\
\hline \multirow[t]{2}{*}{ Average \% Hispanic in Jury Pool's Zip Codes } & 0.00590 & -0.00952 & 0.0508 & -0.00157 & 0.0142 & 0.0201 \\
\hline & $(0.0211)$ & $(0.0395)$ & $(0.0484)$ & $(0.00815)$ & $(0.0158)$ & $(0.0195)$ \\
\hline \multirow[t]{2}{*}{ Average Age of Jury Pool } & 0.00801 & 0.0100 & 0.00404 & 0.00184 & 0.00253 & 0.00199 \\
\hline & $(0.0212)$ & $(0.0219)$ & $(0.0217)$ & $(0.00999)$ & $(0.00999)$ & $(0.0101)$ \\
\hline \multirow[t]{2}{*}{ Proportion Male in Jury Pool } & -0.153 & -0.126 & -0.361 & 0.145 & 0.111 & 0.106 \\
\hline & $(0.620)$ & $(0.652)$ & $(0.651)$ & $(0.257)$ & $(0.257)$ & $(0.258)$ \\
\hline \multirow[t]{2}{*}{ Average Median Income in Jury Pool's Zip Codes } & & 0.00000248 & 0.00000642 & & 0.00000851 & 0.00000848 \\
\hline & & $(0.0000252)$ & $(0.0000249)$ & & $(0.00000992)$ & $(0.00000993)$ \\
\hline \multirow[t]{2}{*}{ Average \% High School Graduates in Jury Pool's Zip Codes } & & -0.0239 & -0.00796 & & 0.0147 & 0.0175 \\
\hline & & $(0.0568)$ & $(0.0564)$ & & $(0.0236)$ & $(0.0242)$ \\
\hline \multirow[t]{2}{*}{ Average \% Foreign Born in Jury Pool's Zip Codes } & & & $-0.109 * *$ & & & -0.0106 \\
\hline & & & $(0.0523)$ & & & $(0.0208)$ \\
\hline \multirow[t]{2}{*}{ Constant } & -0.177 & 1.879 & 1.199 & -0.137 & -2.215 & -2.361 \\
\hline & $(1.252)$ & (4.632) & $(4.565)$ & $(0.578)$ & (2.034) & $(2.055)$ \\
\hline Observations & 104 & 104 & 104 & 436 & 436 & 436 \\
\hline R-squared & 0.007 & 0.009 & 0.052 & 0.011 & 0.019 & 0.019 \\
\hline
\end{tabular}

Note - All regressions use OLS and standard errors are in parentheses. $* * *$, and $* * *$ indicate the coefficient is significant at the $10 \%, 5 \%$, and $1 \%$ level, respectively. 
ST8: Impact of Alternative Jury Pool Race Measures on Trial Outcomes

\begin{tabular}{|c|c|c|c|c|c|c|c|c|}
\hline & \multicolumn{4}{|c|}{$\underline{\text { White Defendants }}$} & \multicolumn{4}{|c|}{$\underline{\text { Black Defendants }}$} \\
\hline & $\begin{array}{c}\text { Sentence } \\
\text { Length } \\
(1)\end{array}$ & $\begin{array}{c}\text { Sentence } \\
\text { Length } \\
(2)\end{array}$ & $\begin{array}{c}\text { Convicted } \\
\text { of a Life } \\
\text { Sentence } \\
(3)\end{array}$ & $\begin{array}{c}\text { Convicted } \\
\text { of a Life } \\
\text { Sentence } \\
\text { (4) }\end{array}$ & $\begin{array}{c}\text { Sentence } \\
\text { Length } \\
(5)\end{array}$ & $\begin{array}{c}\text { Sentence } \\
\text { Length } \\
(6)\end{array}$ & $\begin{array}{c}\text { Convicted } \\
\text { of a Life } \\
\text { Sentence } \\
(7) \\
\end{array}$ & $\begin{array}{c}\text { Convicted } \\
\text { of a Life } \\
\text { Sentence } \\
(8)\end{array}$ \\
\hline Proportion of Jury Pool from Zip Codes $>76 \%$ White & $\begin{array}{l}-34.67 \\
(76.44)\end{array}$ & $\begin{array}{l}-27.9 \\
(92.6)\end{array}$ & $\begin{array}{l}-0.323 \\
(0.877)\end{array}$ & $\begin{array}{l}-0.425 \\
(1.06)\end{array}$ & $\begin{array}{c}46.12 \\
(32.73)\end{array}$ & $\begin{array}{c}8.72 \\
(38.98)\end{array}$ & $\begin{array}{l}0.584 * \\
(0.347)\end{array}$ & $\begin{array}{c}0.305 \\
(0.414)\end{array}$ \\
\hline Proportion of Jury Pool from Zip Codes $<4 \%$ Black & $\begin{array}{l}-26.27 \\
(64.01)\end{array}$ & $\begin{array}{l}-9.121 \\
(80.76)\end{array}$ & $\begin{array}{l}-0.118 \\
(0.735)\end{array}$ & $\begin{array}{l}-0.011 \\
(0.923)\end{array}$ & $\begin{array}{c}23.06 \\
(28.68)\end{array}$ & $\begin{array}{l}-16.85 \\
(33.54)\end{array}$ & $\begin{array}{c}0.288 \\
(0.305)\end{array}$ & $\begin{array}{l}-0.050 \\
(0.357)\end{array}$ \\
\hline Avg. \% Black in Jury Pool's Zip Codes $>14.4 \%$ & $\begin{array}{c}6.816 \\
(6.940)\end{array}$ & $\begin{array}{c}7.746 \\
(9.853)\end{array}$ & $\begin{array}{c}0.091 \\
(0.080)\end{array}$ & $\begin{array}{c}0.146 \\
(0.112)\end{array}$ & $\begin{array}{c}-5.432 * \\
(3.058)\end{array}$ & $\begin{array}{l}-2.104 \\
(4.077)\end{array}$ & $\begin{array}{c}-0.0692 * * \\
(0.0325)\end{array}$ & $\begin{array}{l}-0.0379 \\
(0.0433)\end{array}$ \\
\hline Avg. \% Black in Jury Pool's Zip Codes & $\begin{array}{c}0.946 \\
(1.485) \\
\end{array}$ & $\begin{array}{c}0.079 \\
(3.173) \\
\end{array}$ & $\begin{array}{l}0.012 \\
(.017) \\
\end{array}$ & $\begin{array}{c}0.023 \\
(0.036) \\
\end{array}$ & $\begin{array}{c}-1.539 * * \\
(0.630)\end{array}$ & $\begin{array}{r}-1.7000 \\
(1.334) \\
\end{array}$ & $\begin{array}{c}-0.0179 * * * \\
(0.0067)\end{array}$ & $\begin{array}{r}-0.0216 \\
(.0142)\end{array}$ \\
\hline Observations & 104 & 104 & 104 & 104 & 436 & 436 & 436 & 436 \\
\hline Control for jury pool age, proportion male, and zip code $\%$ Hispanic? & yes & yes & yes & yes & yes & yes & yes & yes \\
\hline Control for jury pool zip code income, education, and foreign born? & no & yes & no & yes & no & yes & no & yes \\
\hline
\end{tabular}

Note: All coefficients presented were estimated from separate OLS regressions, where the outcome variable is given by the column header, the measure of percent of Black (or White) individuals in the jury pool zip code is given by the row, and the additional controls included are noted in the last two rows of the table. Only the coefficient on the core race variable is presented in the table. Standard errors are in parentheses. ***, and *** indicate the coefficient is significant at the $10 \%, 5 \%$, and $1 \%$ level, respectively 